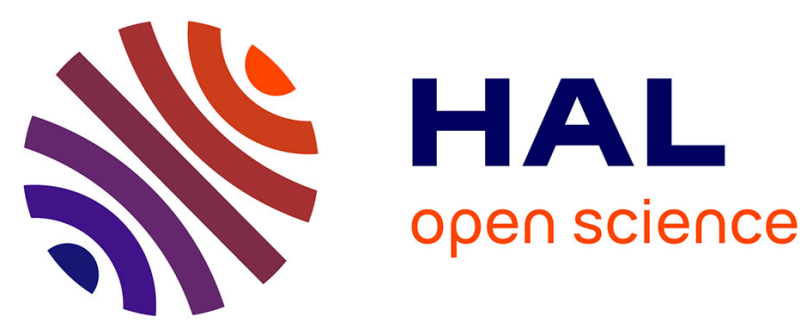

\title{
Bi-phasic dose response in the preclinical and clinical developments of sigma-1 receptor ligands for the treatment of neurodegenerative disorders
}

Tangui Maurice

\section{- To cite this version:}

Tangui Maurice. Bi-phasic dose response in the preclinical and clinical developments of sigma-1 receptor ligands for the treatment of neurodegenerative disorders. Expert Opinion on Drug Discovery, 2020, 10.1080/17460441.2021.1838483 . hal-03020731

\section{HAL Id: hal-03020731 \\ https://hal.science/hal-03020731}

Submitted on 24 Nov 2020

HAL is a multi-disciplinary open access archive for the deposit and dissemination of scientific research documents, whether they are published or not. The documents may come from teaching and research institutions in France or abroad, or from public or private research centers.
L'archive ouverte pluridisciplinaire HAL, est destinée au dépôt et à la diffusion de documents scientifiques de niveau recherche, publiés ou non, émanant des établissements d'enseignement et de recherche français ou étrangers, des laboratoires publics ou privés. 
Bi-phasic dose response in the preclinical and clinical developments of sigma-1 receptor ligands for the treatment of neurodegenerative disorders

Tangui MAURICE

MMDN, Univ Montpellier, EPHE, INSERM, UMR_S1198, Montpellier, France

Correspondance: Dr T. Maurice, MMDN, INSERM UMR_S1198, Université de Montpellier, CC105, place Eugène Bataillon, 34095 Montpellier cedex 5, France. Tel.: +33/0 4671432 91. E-mail: tangui.maurice@umontpellier.fr 


\begin{abstract}
Introduction: The sigma-1 receptor (S1R) is attracting much attention as a target for diseasemodifying therapies in neurodegenerative diseases. It is a highly conserved protein, present in plasma and endoplasmic reticulum (ER) membranes and enriched in mitochondria-associated ER membranes (MAMs). It modulates ER-mitochondria $\mathrm{Ca}^{2+}$ transfer and activation of the ER stress pathways. Mitochondrial and MAM dysfunctions contribute to neurodegenerative processes in pathologies such as Alzheimer's disease, Parkinson's disease, Huntington's disease or Amyotrophic Lateral Sclerosis. Interestingly, the S1R can be activated by small druggable molecules and accumulating preclinical data suggest that S1R agonists are effective protectants in these neurodegenerative diseases.
\end{abstract}

Area covered: In this review, we will present the data showing the high therapeutic potential of S1R drugs for the treatment of neurodegenerative diseases, focusing on pridopidine as a potent and selective S1R agonist under clinical development. Of particular interest is the biphasic (bell-shaped) dose-response effect, representing a common feature of all S1R agonists and described in numerous preclinical models in vitro, in vivo and in clinical trials.

Expert opinion: S1R agonists modulate essential inter-organelles communication altered in all neurodegenerative diseases and activate numerous intracellular survival pathways. Research in the field will continue growing in the near future. The particular cellular nature of this unique chaperone protein must be better understood to facilitate the developement of promising molecules at the clinical stage. 


\section{Introduction: Pathophysiology of neurodegenerative diseases and the sigma- 1 protein track}

Neurodegenerative diseases represent a major public health issue. Alzheimer's disease (AD), Parkinson's disease (PD), amyotrophic lateral sclerosis (ALS), and Huntington disease (HD) present variable incidences and appear from sporadic or genetic causes. The pathophysiological mechanisms affect different neuronal populations and develop through specific symptomatologies. However, they share several common pathological pathways which suggests that common therapeutic approaches could be explored. AD is the most common form of dementia [1]. Clinically, $A D$ is characterized by a progressive alteration of cognitive abilities leading to dementia. The pathological hallmarks comprise the extracellular accumulation of amyloid- $\beta(A \beta)$ species, the appearance of intracellular neurofibrillary tangles, corresponding to aggregated hyper- and abnormally phosphorylated Tau protein, and neuroinflammation [2, 3]. Neurodegeneration results from synergic toxic cascades [2]. Only symptomatic therapies are currently available, among them the cholinesterase inhibitors donepezil, rivastigmine and galantamine, and the noncompetitive NMDA receptor (NMDAR) antagonist memantine. Current research efforts explore both symptomatic, neuroprotective, disease-modifying and potentially curative treatments [for a recent review, see 4].

The clinical symptoms of PD are categorized into motor and non-motor symptoms since deficits in several other neurological functions are also observed [6]. The specific neuropathological hallmarks are the appearance of Lewy bodies, pathological dense bodies composed of $\alpha$-synuclein protein, in dopaminergic nigrostriatal neurons [7]. A key pathological factor is mitochondrial dysfunction, with deficiency in the activity of the respiratory chain complex I, leading to massive oxidative stress. Such alterations can result from genetic mutations affecting $\alpha$-synuclein, parkin, or phosphatase and tensin homolog induced putative kinase (PINK) proteins. There is at present no curative treatment, and therapies such as LDOPA-based treatments or surgery are used for symptom management [6]. 
ALS is the most common type of disease affecting motor neurons [8]. The pathology develops progressively from muscular weakness and atrophy to spasticity due to upper and lower motoneurons degeneration in the cortex, brainstem and spinal cord, eventually leading to death. There is no effective disease-modifying or curative therapy. Riluzole reduces the levels of the main excitatory neurotransmitter, glutamate. It extends survival, but does not slow disease progression [9]. Edaravone can slow physical loss of function in some patients and may work by reducing oxidative stress [10]. ALS etiology is not fully understood and $90 \%$ of ALS cases are sporadic while the other $10 \%$ are familial, suggesting that genetic factors could be aggravating factors in ALS [11].

$\mathrm{HD}$ is a neurodegenerative pathology due to an aberrant expansion of cytosineadenine-guanine (CAG) repeats in the first exon of the huntingtin gene that encodes the Huntingtin $(\mathrm{Htt})$ protein [12]. The $\mathrm{Htt}$ protein is expressed in most tissues and involved in protein trafficking, postsynaptic signaling, vesicle transport, transcriptional regulation and regulation of cell death. Accumulation of CAG repeats result in the production of an elongated polyQ mutant Huntingtin protein ( $\mathrm{mHtt}$ ) forming intracellular and intranuclear aggregates in neurons. These aggregates provoke a lot of different cellular alterations [13-15]. HD patients rapidly develop neuronal loss in the striatum and cerebral cortex, brain atrophy, and significant cognitive, behavioral and physical disabilities [16]. No curative, nor disease-modifying treatment is currently available.

These neurodegenerative diseases, affecting different brain structures, develop from distinct genetic or sporadic causes and present highly specific natural history, distribution and symptoms. However, they all share common traits that can be viewed as common causes or consequences of neurodegeneration. These pathological cellular mechanisms develop differentially but synergistically during the course of the different diseases, ultimately leading to cell loss [17-19]. An effective curative treatment would potentially address the cause of each disease (i.e., gene therapy), while an effective neuroprotective or disease-modifying treatment would target the common pathological impaired mechanisms. Consequently, a curative treatment is therefore expected to be disease-specific while a neuroprotective or disease- 
modifying treatment targeting the commonly impaired pathways is postulated to be effective in different indications.

\section{The sigma-1 receptor as target for neurodegenerative diseases}

One cellular target showing a promising neuroprotective potential in all these indications, with novel ligands currently in clinical evaluation, is the sigma-1 receptor (S1R). Precisely speaking, the S1R is not a typical pharmacological "receptor", since no transduction systems have been identified. Some endogenous molecules, such as neuro(active)steroids, neuropeptides, the trace amine N,N-dimethyltryptamine, and choline [20-22], or physiological signals like oxidative or ER stress $[23,24]$, have been shown to trigger S1R activation. However, no prototypic "endogenous S1R ligand" has been yet established.

The S1R is a transmembrane chaperone protein, highly conserved among species and cell types, present in the ER, nucleus and plasma membranes but particularly enriched in mitochondria-associated ER membranes (MAMs) [23]. S1R interacts with several proteins involved in ER-mitochondria $\mathrm{Ca}^{2+}$ transfer and/or activation of the ER stress pathways [23]. By stabilizing the conformation of the $\mathrm{IP}_{3}$ receptor $\left(\mathrm{IP}_{3} \mathrm{R}\right)$ at MAMs, S1R increases $\mathrm{Ca}^{2+}$ efflux into the mitochondria [25] and activation of the S1R directly controls mitochondrial respiration and generation of mitochondrial reactive oxygen species (ROS), depending on physiological or pathological conditions [26]. As a result of sustained activation, S1R can translocate from ER membranes towards the nuclear and plasma membranes, facilitating transcriptional regulation $[27,28]$, or interacting with ionophores or receptors of neurotransmitters and trophic factors [29]. Interestingly, S1Rs can be activated/inactivated by small druggable molecules, with accumulating preclinical data suggesting that S1R agonists act as protectants in neurodegenerative diseases, including AD, ALS and HD [for recent reviews, see 30-35].

Several drugs acting as S1R agonists are currently in clinical development. The mixed $\mathrm{S} 1 \mathrm{R} / \mathrm{muscarinic}$ acetylcholine receptor (mAChR) agonist tetrahydro- $\mathrm{N}, \mathrm{N}-$ dimethyl-2,2diphenyl-3-furanmethanamine hydrochloride (blarcamesine, ANAVEX2-73, AE37; Fig. 1) and 
the collapsin response mediator protein 2 (CRMP2) inhibitor/S1R agonist 1-\{3-[2-(1benzothiophen-5-yl)ethoxy] propyl\}-3-azetidinol maleate (edonerpic maleate, T-817MA; Fig. 1) are both developed for the treatment of $\operatorname{AD}[36,37]$. The high affinity and selective agonist pridopidine is in clinical development for ALS and HD [38, 39]. The development of S1R ligands is particularly stimulating as they represent a unique mechanism of action. By mainly restoring the altered ER-mitochondria communication, S1R ligands activity is targeted downstream to the classical neurotransmitter receptors, kinases or other enzymes [40].

The clinical development of S1R ligands represents a novel challenge and understanding S1R specificities is key for the optimization of clinical trial design and increasing the chances of success. We will here list the preclinical evidences suggesting the neuroprotective efficacy of S1R agonists in the different preclinical models of neurodegenerative pathologies.

\section{S1R agonists as neuroprotective drugs}

MAMs are domains of interaction between ER and mitochondria which are stabilized by protein bridges and sequester numerous protein assemblies leading to functionalized regulations. $\mathrm{Ca}^{2+}$ exchanges are driven by $\mathrm{IP}_{3} \mathrm{R}$ on the ER and VDAC1/MCU complexes on mitochondrial membranes. Phospholipids, cholesterol, and steroids are also actively exchanged between these two organelles. MAM dysfunction contributes to the neurodegenerative processes in numerous neurodegenerative diseases [41, 42]. Importantly, siRNA knockdown of S1Rs and other MAM proteins such as the phosphofurin acidic cluster sorting protein-2, results in neurodegeneration [43]. In familial AD forms, mutant presenilins, components of the $\mathrm{Y}$ secretase complex processing APP into pathological $A \beta$, are found in MAMs [44, 45]. Toxic $A \beta$ modifies the neuronal ER-mitochondria contacts which appear longer and thinner, a sign of functional alteration [46]. In PD, mitochondrial dysfunction is a central pathological stressor. A pool of $\alpha$-synuclein aggregates accumulates in MAMs and mutations of $\alpha$-synuclein alter MAM functionality [46]. In HD, mutant huntingtin impairs ER-associated degradation and 
trafficking of organelles and vesicles, favoring protein inclusions, deregulating MAM $\mathrm{Ca}^{2+}$ transfer and decreasing normal mitochondrial function [47, 48]. In ALS, TDP-43 aggregation perturbs MAM structure through alteration of VAPB-PTPIP51 protein bridges [49] and downregulates Mitofusin-1/2 bridges [50]. In Multiple Sclerosis (MS), MAM-localized ER stress markers are expressed in lesions observed in patients and in rodent models of experimental autoimmune encephalomyelitis (EAE) [51, 52].

S1R is highly concentrated in MAM [23] and modulates cellular pathways through the regulation of ER-mitochondrial $\mathrm{Ca}^{2+}$ transfer $[23,25]$. Ligands that activate $\mathrm{S} 1 \mathrm{R}$, and are thus considered as "S1R agonists", potentiate bradykinin-induced activation of $I P_{3} R$ and the resulting $\mathrm{Ca}^{2+}$ transfer from the ER into the mitochondria [25]. S1R antagonists fail to do so, leaving $\mathrm{Ca}^{2+}$ transfer at its basal level but preventing S1R agonist-induced potentiation [25]. This cellular activity was used as a first in vitro test to define agonist/antagonist activity of S1R ligands. More recently, S1R activity was also related to the dissociation of S1R from the ER stress protein BiP/GRP78 [23]. This cellular response showed a very coherent pharmacology with the previously observed drug effect on $\mathrm{ER} \mathrm{Ca}^{2+}$ mobilization. The agonist/antagonist activity of ligands is now preferentially tested using the cellular assay based on S1R/BiP dissociation. However, S1R agonists act primarily on MAM alterations to restore cellular homeostasis. Pathophysiological alteration in MAM is central in neurodegenerative disorders [41, 42], and provides explanation for the efficacy of S1R agonists described in the different preclinical models.

- Alzheimer's disease. The S1R agonists 2-(4-morpholinethyl)-1phenylcyclohexanecarboxylate hydrochloride (PRE-084; Fig. 1) and (-)-methyl (1S,2R)-2-\{[1adamantyl(methyl)amino]methyl\}-1-phenylcyclopropanecarboxylate ((-)-MR-22; Fig. 1) attenuated $A \beta_{25-35}$-induced toxicity in vitro [53]. 4-[2-[(6-Ethoxy-1H-benzimidazol-2yl)sulfanyl]ethyl]morpholine (fabomotizole; Fig. 1), a mixed S1R and sigma-2 receptor (S2R)

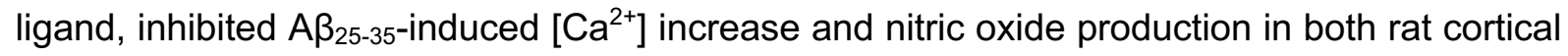
neurons and microglial cultures [54, 55]. Fabomotizole also decreased neuronal cell death, and increased the levels of the pro-apoptotic proteins Bax and caspase-3. It also augmented 
the level of the anti-apoptotic protein, Bcl-2 [55]. Interestingly, Fabomotizole acted directly on microglial cells as it decreased microglial activation in response to $A \beta_{25-35}$ and prevented the decrease in microglial ATP. In vivo, numerous S1R agonists, including PRE-084, (-)-MR22, tetrahydro-N,N-dimethyl-5,5-diphenyl-3-furanmethanamine hydrochloride (ANAVEX1-41, AE14; Fig. 1), blarcamesine, dehydroepiandrosterone and pregnenolone sulfates, were found to be neuroprotective in pharmacological rodent models of AD [56-62]. These drugs effectively prevented learning impairments and oxidative stress, cholinergic alterations, neuroinflammation, apoptosis, and cell loss in different models, including $A \beta_{25-35}$, aluminium chloride, or 192 lgG-saporin induced toxicity. S1R ligands also showed some diseasemodifying effects since they decreased APP and $A \beta_{1-42}$ accumulation in the brain $[60,62]$, GSK-3 $\beta$ activation and Tau hyperphosphorylation [62]. Long-term treatment with 1-(2,8dimethyl-1-thia-3,8-diazaspiro[4.5]dec-3-yl)-3-(1H-indol-3-yl)propan-1-one (ANAVEX3-71, AF710B; Fig. 1), a mixed M1 mAChR/S1R agonist, attenuated learning impairment and BACE1 levels, GSK3 $\beta$ activity, p25/CDK5 levels, and neuroinflammation in 3xTg AD mice [63]. ANAVEX3-71 also increased amyloid cerebrospinal fluid clearance and levels of a synaptic marker in McGill-R-Thy1-APP transgenic (Tg) AD rats [64]. Autophagy is key in protein clearance and dysfunction in autophagy is directly linked to the pathogenesis of $A D$ and other neurodegenerative diseases. Activation of S1R by ANAVEX2-73 enhanced autophagic flux in human cells and in C. elegans and had a positive effect on proteostasis [65]. Therefore, different S1R agonists have been tested in several pharmacological and transgenic models of $A D$ and coherently showed efficacy on several pathological alterations and behavioral consequences. As the S1R mechanism of action primarily relates to mitoprotection through functional facilitation of MAMs, it is highly conceivable that S1R drugs act as neuroprotectant on neurons and glial cells that degenerate in the pathology. Whether this translate into neuroprotection and disease-modifying effects in the patient will be shown in the future clinical trials.

- Parkinson's disease. S1R agonists were also tested more recently in PD models, first using the reference ligand PRE-084. In the 6-hydroxydopamine (6-OHDA)-lesioned mouse 
model of PD, the drug improved spontaneous forelimb use [66]. In parallel to behavioural recovery, the density DA fiber increased in the denervated striatum, DA levels partially increased, and brain-derived neurotrophic factor (BDNF) and glia-derived neurotrophic factor (GDNF) neurotrophic factors were up-regulated $[66,67]$. No effect was observed in mice with a deletion of the S1R gene (S1R-KO) that were lesioned with 6-OHDA. Interestingly, astrocytes and neurons in the substantia nigra and striatum were positively immunoreactive for S1R and S1R agonists affected the protein intracellular distribution. Furthermore, a comparative study between fabomotizole and PRE-084, injected over 14 days, showed normalization of motor dysfunction, decreases in dopamine content in the 6-OHDA-lesioned striatum, and loss of $\mathrm{TH}+$ neurons in the substantia nigra of ICR mice [68]. No study yet examined the S1R drugs in alternative models of PD, such as $\alpha$-synuclein- or LRRK2-based models. A recent study was based on DAT promoter-mediated Cre transgenic mice established to generate tamoxifeninducible Dicer conditional knockout mice and to present a progressive loss of DA neurons in PD [69]. It confirmed the neuroprotective activity of PRE-084 on Dicer cKO-induced loss of DA neurons and motor impairments. S1R drugs may therefore be potentially effective on both motor and non-motor symptoms of PD, particularly in PD related dementia.

- Amyotrophic lateral sclerosis. The role of S1R in ALS is of particular interest as lossof-function mutations in the S1R (c.304G>C, p.E102Q and c.283dupC, p.L95fs) were associated with a severe juvenile form of ALS [70, 71] and a missense mutation was associated with an adult onset form of ALS [72]. The pathogenicity of the ALS S1R ${ }^{\mathrm{E} 102 \mathrm{Q}}$ mutation and the beneficial impact of S1R over-expression in the ALS context was recently demonstrated in vivo in transgenic Drosophila expressing human wild-type S1R or mutant $S 1 R^{E 102 Q}$ [73]. Neuronal expression of the mutant S1R induced abnormal eye morphology, locomotor deficits, pathological mitochondrial fragmentation, reduced ATP levels and a higher fatigability at the neuromuscular junction during high energy demand. On the other hand, expression of wild-type S1R rescued locomotor activity, enhanced resistance to oxidative stress and increased ATP levels in flies expressing TDP43 [73]. In the ALS SOD1 ${ }^{\text {G93A }}$ mice, deletion of the S1R gene (S1R-KO) exacerbated disease progression and decreased lifespan 
of the mice [74], while treatment with S1R agonists extended the lifespan of SOD1 ${ }^{\text {G93A }}$ mice $[75,76]$. PRE-084 treatment ameliorated locomotor capacities and survival of motoneurons in presymptomatic and early symptomatic SOD $1^{\mathrm{G} 93 \mathrm{~A}}$ mice as well as in the wobbler mouse, a model of spontaneous motoneuron degeneration [77]. PRE-084 increased BDNF levels in the gray matter, increased the survival of motoneurons, attenuated the paw abnormalities, improved grip strength, and attenuated the overactivation of astrocytes and microglia. In this indication, S1R appears not only protective through enhanced activity by S1R agonists, but also involved in the pathological phenotype through the E102Q mutation in a juvenile form of ALS. Moreover, as data accumulate showing that S1R drugs are protectants in several preclinical models of ALS, and putatively through different cellular mechanisms, ALS clearly appears as a first-intent indication for S1R drugs.

- Huntington's disease. PRE-084 prevented cell toxicity and induced antioxidative and anti-apoptotic responses in PC6.3 cells overexpressing $\mathrm{mHtt}$ [78]. Accumulation of S1R was observed in the nuclear inclusions in HeLa cells transfected with $\mathrm{N}$-terminal mHtt [79]. Both genetic silencing of S1R with small interfering-RNA (siRNA) and specific inhibition of the proteasome with epoxomicin significantly enhanced the accumulation of aggregates in the cytoplasm and nucleus. In contrast, mHtt-containing nuclear inclusions decreased in number and size after S1R overexpression [79]. Therefore, S1R expression and activity directly impact mHtt physiopathology and the protein is also a pertinent target in HD.

These observations demonstrated the therapeutic potential of S1R ligands in preclinical models of neurodegenerative diseases. However, studies were based on either non-selective S1R ligands, such as blarcamesine or fabomotizole, having potentially secondary targets, or on selective compounds, like PRE-084, which are in the public domain for years and could be used as prototypic ligands but not suitable for clinical development. Therefore, the development of novel and highly selective S1R agonists is still particularly valuable. Among these, pridopidine appears today as the most promising candidate and accumulating data accumulate that show its efficacy in preclinical models and promising profile for clinical trials. 


\section{Pridopidine as a promising potent and selective S1R neuroprotectant}

4-[3-Methanesulfonyl-phenyl]-1-propyl-piperidine (pridopidine, ACR16; Fig. 1) is a prototypic example of S1R drug that must be emphasized in the present review as: (i) it is a high affinity selective S1R agonist, contarily to blarcamesine, fluvoxamine or dextromethorphan; (ii) it is presently at the clinical stage; (iii) it is developed in different indications (HD and ALS); and (iv) it showed bell-shaped dose- or concentration-dependent responses in vitro and in vivo. Pridopidine was originally postulated to act as a "dopamine stabilizer" via low affinity antagonism at the dopamine D2/D3 receptors [80]. The drug was later found to bind the S1R with high nanomolar affinity, i.e., with a 28-fold higher affinity as compared to D3 receptors and a 518-fold higher affinity as compared to D2 receptors (Table 1) [81, 82]. In vivo PET imaging in rats demonstrated that pridopidine, at pharmacologically active doses, selectively occupies the S1R rather than dopamine receptors [83]. Pridopidine is also selective for S1R vs. S2R, with a 96 fold selectivity (Table 1). The drug is therefore considered to be a highly selective S1R agonist. Its neuroprotective properties were demonstrated in several preclinical models of neurodegenerative diseases.

- Alzheimer's disease. Pridopidine protected mushroom spines from $A \beta_{1-42}$ oligomer toxicity in both mouse primary hippocampal cell cultures and in cultures from APP-KI and PS1$\mathrm{KI}$ mice [33]. Oral pridopidine treatment also rescued mushroom spines in vivo, in aged PS1KI-GFP mice. Furthermore, the drug reversed long-term potentiation (LTP) and neuronal storeoperated $\mathrm{Ca}^{2+}$ entry (nSOC) defects in hippocampal slices exposed to $A \beta_{1-42}$ oligomers. Pridopidine restored ER calcium levels in PS1-KO, PS1-KI and PS2 KO neurons [33]. Genetic deletion of S1R with lenti-viral shRNA prevented the synaptoprotective effects of pridopidine in PS1-KI cultures, suggesting that the stabilization of mushroom spines in $A D$ models is mediated by the S1R.

- Parkinson's disease. Pridopidine was tested in the 6-OHDA-lesioned mouse model [67], demonstrating a significant improvement in deficits of forelimb use as measured by the cylinder test and the stepping test, as well as rescuing the ipsilateral rotational bias typical in 
these hemiparkinsonian mice. Behavioral recovery was shown by a significant protection of nigral dopamine cell bodies, increase in the density of dopaminergic fibers in the striatum, upregulation of the neurotrophic factors GDNF and BDNF in the striatum, and the downstream phosphorylation of Erk1/2 [67]. In 6-OHDA-lesioned mice where the S1R was deleted, the beneficial effects of pridopidine were abolished, indicating the observed protective effects are S1R mediated.

- Amyotrophic lateral sclerosis. In vivo, in the SOD $1^{\mathrm{G} 93 \mathrm{~A}}$ mouse model of ALS, pridopidine showed a marked reduction in mutant SOD1 aggregation in the spinal cord as well as attenuation of the disruption of neuromuscular junctions, leading to subsequent muscle preservation [84]. In vitro, in SOD $1^{\mathrm{G} 93 \mathrm{~A}}$ neuro-muscular co-cultures, pridopidine attenuated axonal transport deficits, neuromuscular junction disruption, and motoneuron death [84]. These effects were mediated by S1R activation as deletion of the S1R gene completely abolished pridopidine's protective effects. Therefore, pridopidine efficiently improves several pathological consequences of ALS through its S1R agonist action.

- Huntington's disease. Pridopidine was comprehensively examined for its neuroprotective activities in preclinical models of HD. In conditionally immortalized mouse striatum knock-in cells expressing endogenous levels of wild-type $\mathrm{Htt}$ or $\mathrm{mHtt}$, pridopidine protected cells from apoptosis [85]. The R6/2 transgenic mouse, which expresses exon 1 of human $\mathrm{Htt}$ with approximately 160 CAG repeats, develops an aggressive disease pathology within 10-15 weeks. Pridopidine treatment improved motor performance and increased the survival of R6/2 mice [85]. Pridopidine, through S1R activity and Erk activation, enhanced expression of BDNF and dopamine and cAMP-regulated neuronal phosphoprotein 32 (DARPP32) protein in the striatum of $\mathrm{R} 6 / 2$ mice and reduced the size of $\mathrm{mHtt}$ aggregates. Pridopidine activated neuroprotective pathways including the BDNF and AKT/PI3 pathways known to be impaired in HD [86]. Additionally, pridopidine upregulated the dopamine D1 receptor and glucocorticoid receptor pathways, known to promote neuronal plasticity and survival. In the YAC128 mouse model of HD, longitudinal treatment with pridopidine from a pre-symptomatic stage ( 1.5 months of age) up to symptomatic disease stage at 12 months of 
age (total of 10.5-months of treatment) improved motor coordination and motor learning and reduced anxiety- and depressive-like phenotypes in these HD mice [87]. Interestingly, pridopidine exerted beneficial effects also at the transcriptional level. RNA-seq analysis of YAC128 mice treated with pridopidine showed reversion of striatal transcriptional deficits and upregulation of disease-specific genes which are downregulated in HD [87]. The broad effects of pridopidine in restoring the striatal transcriptomic alterations particularly related to synaptic transmission and neuroprotective pathways disturbed in HD, were further demonstrated in the striatum of YAC128 HD mice, where pridopidine treatment rescued the impaired expression of BDNF, glucocorticoid receptors, D1 dopamine receptors and cAMP pathways. In vitro, pridopidine protected $\mathrm{mHtt}$-transfected mouse primary striatal and cortical neurons, as well as HD patient-derived induced pluripotent stem cells (iPSCs) from mHtt-induced cell death, with an EC50 in the nanomolar range. These effects were blocked using a S1R antagonist or a deletion of the S1R gene [88]. In cultured cortical neurons from wild-type or YAC128 mice, YAC128 neurons show an impaired ability to induce homeostatic synaptic plasticity (HSP) in response to tetrodotoxin (TTX) treatment. HSP is an essential neuronal process enabling new learnings and cognitive flexibility. In HD, impaired HSP precedes the onset of symptoms. Pridopidine restored the TTX-induced HSP in YAC128 neurons via S1R activation [89].

Taken together, these observations demonstrate that pridopidine has neuroprotective properties in preclinical models of neurodegeneration through S1R activation. It supports the idea that pridopidine is an attractive drug for the treatment of neurodegenerative disorders. These observations also further confirm that S1R activity is beneficial in different neurodegenerative processes.

In the clinic, pridopidine demonstrated a beneficial effect by maintaining total functional capacity (TFC) in early HD patients. The drug is currently undergoing further clinical development for the treatment of HD (see Table 2, for past and current trials) and ALS [38, 39].

\section{S1R agonists display bi-phasic dose-response curves}


Intrinsic activity, selectivity vs. other pharmacological targets (notably S2R) or potential offtargets, and absorption, distribution, metabolism, and excretion (ADME) parameters must be taken into consideration in the clinical development of drugs, and particularly new S1R ligands. Another important consideration for S1R agonists is the bi-phasic dose-response curve observed very regularly in biological responses, suggesting that an adequate concentration or dose of the ligand is required to induce an optimal effect. This is of high importance in the clinical development of S1R ligands, as the effective dose selection may rely on numerous interacting factors related to the pathology, patient history and dosage form.

Bi-phasic (bell-shaped) dose-response effects were originally introduced through the notion of hormesis, and particularly discussed by Calabrese [for reviews and main contributions, see 90-93]. Hormesis is defined as a paradoxical beneficial effect seen with low doses and less beneficial effect at higher doses. Applied to the S1R chaperone protein, hormesis corresponds to the bi-phasic effect observed in specific as well as more integrated physiological or behavioral responses. We will now detail the numerous observations showing that S1R agonists respond to the definition of bi-phasic effects in pre-clinical, in vitro or in vivo models, as well as in clinical trials. Almost no contrary data have been reported when drugs are tested in a sufficiently wide dose-range, thus indicating that hormesis is likely an intrinsic characteristic of S1R activity. Some typical examples are presented in Fig. 2.

\subsection{Preclinical observations}

The first observations that a pharmacological effect of S1R activation resulted in a bi-phasic concentration-response curve were made during the early 1990s, on S1R-induced modulation of NMDA-evoked responses in vitro and in vivo. Release of $\left[{ }^{3} \mathrm{H}\right]$ norepinephrine from rat hippocampal slices can be evoked by administration of $100 \mu \mathrm{M}$ NMDA. This NMDA response was potentiated by up to $20 \%$ of the basal value by low (3-50 nM) concentrations of S1R ligands including ditolylguanidine (DTG; Fig. 1), (R)-(+)-N-cyclopropylmethyl-a-ethyl-N-methyla-[(2E)-3-phenyl-2-propenyl)benzenemethanamine hydrochloride (igmesine, JO-1784; Fig. 1), 
and N-n-propyl-3-(3-hydroxyphenyl)piperidine ((+)-3-PPP; Fig. 1) or the peptides neuropeptide Y or peptide YY [94, 95] (Fig. 2a). All drugs effects followed a bi-phasic curve and disappeared at higher concentrations in the $\mu \mathrm{M}$ range. Similarly, In vivo, the NMDA-induced firing activity of CA3 pyramidal neurons was increased by 2 - to 10 -fold with low doses of DTG $(0.5-3 \mu \mathrm{g} / \mathrm{kg}$ i.v.), igmesine (1-100 $\mu \mathrm{g} / \mathrm{kg}$ i.v.) (Fig. 2b), and (+)-pentazocine (1-100 $\mu \mathrm{g} / \mathrm{kg}$ i.v.), among others [96-100]. These effects were suppressed at higher doses $(0.1 \mathrm{mg} / \mathrm{kg}$ i.v. for igmesine or 5 $\mathrm{mg} / \mathrm{kg}$ i.v. for DTG) following a bi-phasic dose response curve [97, 100]. More generally, high doses of the S1R agonists, DTG, igmesine, (+)-cis-N-methyl-N-[2,(3,4-dichlorophenyl) ethyl]2-(1-pyrrolidinyl) cyclohexylamine (BD737; Fig. 1) and 1'-benzyl-3,4dihydrospiro-[naphthalene-1-(2H),4'-piperidine] (L-687,834; Fig. 1) suppressed the potentiation induced by low doses of these drugs, demonstrating that at high doses, they acted in a similar way to the S1R antagonists haloperidol, 4-methoxy-3-(2-phenylethoxy)-N,Ndipropylbenzeneethanamine (NE-100; Fig. 1) or BD1047 [100, 101]. The descending phase of the curve could be due to either a direct NMDA receptor antagonistic effect of the drugs at high doses, or to S2R activation. S1R activation may differently impact NMDA receptor activity, directly or indirectly through regulation of intracellular $\mathrm{Ca}^{2+}$ levels [102].

Of note, the S1R agonist 1-[2-(3,4-dimethoxyphenyl)ethyl]-4-(3phenylpropyl)piperazine (cutamesine, SA4503; Fig. 1) also increases the firing rate of rat dorsal raphe nucleus 5-HT neurons in vivo in a bi-phasic manner, with a maximum effect of $+90 \%$ at $10 \mathrm{mg} / \mathrm{kg}$, and no effect at $40 \mathrm{mg} / \mathrm{kg}$ (Fig. 2c) [104]. The authors highlighted the coherence with the previously mentioned modulation of NMDA-induced firing activity observed in hippocampal slices.

At the cellular level, modulation of $\mathrm{Ca}^{2+}$ mobilization from the ER is considered a primary S1R-mediated event. The bradykinin-induced increase in $\left[\mathrm{Ca}^{2+}\right]_{i}$ in NG-108 cells is potentiated by (+)-pentazocine $(0.001-10 \mu \mathrm{M})$, PRE-084 $(0.01-10 \mu \mathrm{M})$ or the neuro(active)steroid pregnenolone sulfate $(0.1-100 \mu \mathrm{M})$, in a bi-phasic manner with a peak effect between 0.1-1 $\mu \mathrm{M}$ (Fig. 2d) [25]. Similar bi-phasic effects were found for the S1R agonist PRE-084 or the mixed NMDA receptor antagonist/S1R agonist 3,5-dimethyl- 
tricyclo[3.3.1.1 $1^{3,7}$ decyl amine (memantine; Fig. 1) with peak effects at 1 and $10 \mu \mathrm{M}$, respectively [104]. The potentiating action of S1R drugs on bradykinin-induced $\left[\mathrm{Ca}^{2+}\right]_{\mathrm{i}}$ increase was not affected by either the NMDA receptor blocker dizocilpine or the GABAA receptor antagonist (+)-bicuculline but was antagonized by the selective S1R antagonists NE-100 or BD1047 [25, 104]. These observations were the first to demonstrate that S1R ligands affect bradykinin-induced $\left[\mathrm{Ca}^{2+}\right]_{i}$ by facilitating $\mathrm{IP}_{3}$ receptor activity on the ER where S1Rs are expressed. Moreover, the descending phase of the bi-phasic dose-response was proposed to be due to a S1R induced suppressive effect on $\mathrm{IP}_{3}$ formation at high doses [25].

A cellular consequence may be related to a physiological oxidative signal induced by S1R (Fig. 2e) [26]. Indeed, in raw brain mitochondria preparations, S1R agonists increased ROS in a dose-dependent but bi-phasic manner. The effect was $\mathrm{Ca}^{2+}$ dependent, thus likely consequent to the regulation of $\mathrm{IP}_{3} \mathrm{R}$-driven exchanges, and related to a S1R-mediated potentiation of the activity of complex I of the mitochondrial respiratory chain [26].

At the behavioral level, S1R agonists are potent antidepressant and anti-amnesic drugs. In particular, in line with the potentiating effect on $\left[\mathrm{Ca}^{2+}\right]_{i}$ mobilization and on NMDAevoked responses in the hippocampus, the effects of the ligands on the learning impairments provoked by the NDMAR non-competitive antagonist dizocilpine (MK-801) were extensively examined. DTG, [2S-(2a, 6a,11R*)]-1,2,3,4,5,6-hexahydro-6,11-dimethyl-3-(2-propenyl)-2,6methano-3-benzazocin-8-ol hydrochloride (Alazocine, (+)-N-allylnormetazocine hydrochloride, (+)-SKF-10,047; Fig. 1), PRE-084 (Fig. 2f), cutamesine, or blarcamesine attenuated dizocilpine-induced spontaneous alternation or passive avoidance deficits with a bi-phasic dose response [58, 105-108]. Furthermore, S1R ligands attenuated the learning deficits induced by cholinergic blockade. (+)-Pentazocine, cutamesine, or ANAVEX1-41 prevented the learning deficits induced by the mAChR antagonist scopolamine in a haloperidol-, NE-100-, or BD10,047-sensitive manner and with a bell-shaped dose-response curve [109, 110]. Similar bi-phasic effects were observed in pathological models of amnesia, including pathological ageing as observed in senescence-accelerated mice (SAM) [111], basal forebrain lesions [109, 
112] or the pharmacological $A D$ model induced by intracerebroventricular injection of oligomerized $A ß_{25-35}$ amyloid peptide $[58,113]$.

Moreover, several ligands were recently characterized as positive allosteric modulators of S1R [32]. Among them, 4R,5S-methylphenylpiracetam (E1R; Fig. 1), ( \pm )-2-(3-chlorophenyl)3,3,5,5-tetramethyl-2-oxo-[1,4,2]-oxazaphosphinane (OZP002; Fig. 1), and N-ethyl-1-[3(trifluoromethyl)phenyl]propan-2-amine (fenfluramine; Fig. 1) showed a S1R-dependent memory-improving effects in the scopolamine or dizocilpine models [114-116]. E1R, however, was the only modulator that showed a dose-dependent improvement of memory in drug-naïve animals [114]. The effects were bi-phasic and fully antagonized by the S1R antagonist NE100. It is remarkable to note that in all these different studies and models, the peak active doses are consistently between 0.3 and $1 \mathrm{mg} / \mathrm{kg}$, after subcutaneous (s.c.) or intraperitoneal (i.p.) administration, irrespective of the drug and model.

In neuroprotection studies, a bi-phasic dose-response curve was observed for several S1R drugs in $A D$ and PD models. When simultaneously injected with $A \beta_{25-35}$ peptide, ANAVEX1-41 protected from the A $\beta$-induced learning deficits (Fig. $2 \mathrm{~g}$ ) or oxidative stress at 30 and $100 \mu \mathrm{g} / \mathrm{kg}$ i.p., but not at higher doses [57]. PRE-084 or pridopidine, at $0.3 \mathrm{mg} / \mathrm{kg}$, but not at a higher $(1 \mathrm{mg} / \mathrm{kg})$ doses, induced neurohistological restoration of dopaminergic neurons in the substantia nigra of 6-OHDA-lesioned mice (Fig. 2h) [66, 67]. Moreover, in cultured cortical neurons from YAC128 HD mice, pridopidine restored TTX-induced homeostatic synaptic plasticity in a bi-phasic manner showing an effect at $1 \mu \mathrm{M}$, but not at 0.1 or $10 \mu \mathrm{M}$ [89].

\subsection{Clinical aspects}

In a different indication, but with a result highly illustrative for our talk, igmesine was evaluated in a multicentric phase II clinical trial for the treatment of depression [117]. Two groups were treated with either $25 \mathrm{mg}$ or $100 \mathrm{mg}$ daily regimen of igmesine and compared to placebo or fluoxetine $20 \mathrm{mg}$. The total Hamilton depression rating scale (HAM-D) score showed a significant beneficial effect with the low dose $(25 \mathrm{mg})$ igmesine in an out-patient sub-group 
compared to placebo. The higher igmesine dose $(100 \mathrm{mg})$ failed to show a significant effect [117].

PRIDE-HD was a phase 2 exploratory clinical trial evaluating pridopidine at $45 \mathrm{mg}$ twice daily (bid), $67.5 \mathrm{mg}$ bid, $90 \mathrm{mg}$ bid, or $112.5 \mathrm{mg}$ bid in HD patients (Table 2). At 52-weeks, low dose pridopidine (45 $\mathrm{mg}$ bid) showed a beneficial effect maintaining total functional capacity (TFC). The beneficial effect on TFC gradually decreased with higher dosages [39]. $45 \mathrm{mg}$ bid was also the most efficacious dose improving motor function as measured by the quantitative motor assessment (Q-motor), with higher doses showing less effect [39]. Observation of biphasic curves in clinical readouts using S1R drugs, highlights the importance of a proper and rigorous dose range finding in the design of clinical trials.

\subsection{Possible mechanisms for the bi-phasic drug effect}

The observation of bi-phasic dose-response curve for drugs is common in neuroscience and demonstrated for neuronal survival, neurite outgrowth, learning and memory, anxiety, depression, addiction and neuroprotection studies [92]. For many pharmacological targets, the bi-phasic dose-response model likely integrates upstream signaling pathways, stress response mechanisms, interaction with endogenous ligands, permanence of a ceiling effect in the cellular response, interfering responses as well as undesired drug-induced side effects. The exact mechanism related to S1R bi-phasic curves has not been extensively addressed in experimental studies and it is unlikely that a unique underlying mechanism is at work from the cellular to the clinical level. Indeed, several pharmacological characteristics of S1R possibly contribute to the observed drug effects that we will now detail.

- $\quad \mathrm{S} 1 \mathrm{R}$ is present in both monomeric and oligomeric states. The S1R is not a classical transmembrane receptor which induces specific modes of signal transduction typical to a certain cell type, physiopathological condition and mode of ligand-receptor interaction. The S1R is a chaperone protein, activated by physiological signals [24] and partnering with numerous cellular client proteins including various types of ion channels and G-protein coupled receptors. The activation of S1R results in association, dissociation, or heterodimerization 
events [23, 118-122]. S1Rs can be found in either monomeric or oligomeric forms in physiological conditions and the binding of ligands directly impacts its state of oligomerization [123] (Fig. 3a). Agonists such as (+)-pentazocine are proposed to favor monomers and dimers while antagonists such as haloperidol, favor higher order of S1R oligomers [124]. The S1R thus exists in cells in multiple oligomeric forms and S1R ligands alter these oligomeric structures, suggesting that the S1R oligomerization state regulates its functional activity [125]. It is therefore highly conceivable that a given S1R-mediated physiological response depends on a specific S1R oligomerization state [123, 1265 126]. Thus, a S1R ligand-induced activity will depend on the specific drug effect on oligomerization. In other words, a S1R effect relies on the drug intrinsic activity inducing S1R monomerization, and on the intrinsic monomer/oligomer dynamics. An agonist activates the S1R by favoring monomerization state and promoting its association with a client protein, e.g., $\mathrm{IP}_{3} \mathrm{R}$ or $\mathrm{BiP}$. The mixed dynamics or heterodimerization with partner proteins and monomer/oligomer intrinsic regulation likely leads to a saturable level and consequently to a non-linear dose-response dependency (Fig. 3a).

- S1Rs have particular cellular dynamics. It was previously shown in a series of remarkable studies by Hayashi \& Su $[23,127,128]$, that S1R specifically targets lipid droplets on the ER by forming specific lipid microdomains that contain neutral lipids and caveolin-2, a cholesterol-binding protein present in lipid rafts [127]. The S1R forms detergent-resistant raftlike lipid microdomains, the buoyancy of which is different from that of plasma membrane lipid rafts. S1R agonists, like (+)-pentazocine, provoked the disappearance of S1R from the microdomains. Moreover, over-expression of S1R in cells resulted in a wider distribution of neutral lipids all over the ER network, decreasing cholesterol in plasma membranes and promoting bulbous ER aggregation [127]. The authors therefore introduced the notion that S1Rs could be unique ER proteins that regulate the compartmentalization of lipids on the ER and their export from it to plasma membrane or cytosolic lipid droplets.

The S1R presents dynamic translocations within cells [128]. For instance, administration of the S1R agonist (+)-pentazocine to cells provoked a significant decrease of S1R from ER lipid droplets and a diffused distribution of the protein along the ER network, 
toward the nuclear envelope and neurites [128]. Dynamic translocation of S1Rs affected transport and distribution of lipids and other mediators among organelles and compartments in neuronal cells. Treatments with S1R ligands regulated S1R protein expression. For instance, S1R hippocampal expression was increased in mice that chronically consumed alcohol for 4 months. Subcellular fractionation experiments revealed that an agonist treatment increases S1R localization in the plasma membrane fraction, while an antagonist treatment restricted its expression to the ER fraction [129]. Noteworthily, S1Rs have been identified on the plasma membrane in cultured cells [130, 131] and in dorsal root ganglion cells [132], besides ER and nuclear envelope. But, in the mouse retina, S1R was detected only in the nuclear envelope in bipolar cells and in the nuclear envelope and the ER as well in ganglion cells [133]. The precise cellular localization of S1R may therefore depend on cellular types or experimental models. The action of S1R ligands will therefore depend on the protein oligomerization state, which is directly related to its subcellular localization and its presence at the surface or intracellularly.

It is therefore conceivable that specific cellular effects mediated by S1R agonists are dependent on particular cellular localization of S1R proteins (Fig. 3b). For example, (i) the rapid effects of S1R agonist on learning and memory could be related to $\mathrm{Ca}^{2+}$ exchanges driven between the plasma membrane ionophores and MAMs, or (ii) long-term neuroprotective effects on neuronal cells could be attributed to stabilization of MAMs and mitochondrial homeostasis. Therefore, over-activation using high doses of ligands may impact the cellular compartmentalization of S1R to an extent that counteracts the protein activity at its primary site of action. This could also result in the observed bi-phasic dose-response dependency (Fig. $3 b)$.

- $\quad$ S1R activity involves the BDNF system. Accumulating evidence indicate an important role of S1Rs in the regulation of the BDNF system in the brain. S1R activation enhances BDNF levels and secretion in the hippocampus and cortex [134-137]. Both anti-amnesic, antidepressant and neuroprotective effects of S1R agonists rely on the regulation of BDNF activity [66, 77, 85, 86, 138 139]. Moreover, BDNF trophic effects also demonstrated bi-phasic doseresponse curves. For instance, BDNF protected cortical 5-HT neurons from neurotoxin $\mathrm{p}-$ 
chloroamphetamine (PCA) induced cell death [140]. Chronic BDNF infusions stimulated the sprouting of both intact and PCA-lesioned 5-HT axons, leading to a hyper-innervation at the neocortical infusion site [141]. BDNF infusions also induced a sustained local activation of its high affinity TrkB receptor. The dose-response effect of BDNF to stimulate 5-HT sprouting and TrkB signaling demonstrated a bi-phasic curve with maximal efficacy at intermediate BDNF doses which declined at higher doses [141]. In a model of motor axonal regeneration after tibial motoneurons axotomy in rats, low doses of exogenously applied BDNF promoted axonal regeneration and fully reversed the negative effects of delayed nerve repair, while high doses of BDNF inhibit motor axonal regeneration [142]. These observations of BDNF bi-phasic effects are shared in numerous models and indications and are explained by the regulatory impact of BDNF on its receptor (TrkB) expression (Fig. 3c). Excessive BDNF provokes a decline in the full-length, functional TrkB protein, but not the non-active truncated TrkB protein or TrkB mRNA levels [141]. The inhibitory actions of high dose BDNF on axonal regeneration are also reversed by BDNF binding to p75 neurotrophic receptor (p75NTR), the low affinity BDNF receptor [142]. Thus, activation of p75NTR receptors, together with down-regulation of the full-length TrkB isoform, likely mediates the inhibitory effects observed at high doses of BDNF. As S1R agonists activate the BDNF system, which is known to exert effects in a biphasic dose response manner, this cellular activity potentially contributes to the bi-phasic effects observed by S1R ligands in numerous model systems (Fig. 3c).

- Drug selectivity vs. S2R. Noteworthily, several drugs are not selective for S1R vs. S2R. The S2R is another intracellular chaperone protein that is also widely expressed in the brain. The S2R was initially claimed to be the progesterone receptor membrane component 1 (PGRMC1), since the latter was irreversibly labeled in rat liver with WC-21, a sigma-2 ligand bearing a photoactive azide and a fluorescein isothiocyanate groups [143]. However, S2R was recently cloned using a chemical biology approach and identified as TMEM97, an ER-resident transmembrane protein that regulates the sterol transporter NPC1 [144]. Although the two proteins, $S 1 R$ and $S 2 R$, are not genetically related, they share similarities in their pharmacological profile and some S1R ligands also show high affinity for S2R, such as 
haloperidol, DTG, or fabomotizole [145-149]. Several S2R antagonists are shown to have beneficial effects in neurodegenerative diseases such as $A D$ and are currently evaluated in clinical trials [150-152]. However, S2R agonists also induce neurodegeneration [151] and apoptosis, which makes them attractive as anti-cancer drugs [153]. Therefore, a relatively nonselective S1R agonist, with lower affinity, agonistic activity at $S 2 R$ may activate the $S 2 R$ at high doses. This could decrease the neuroprotective effects of S1R and also explain the biphasic response seen with some non-selective S1R agonists [149, 153].

\section{Conclusions: considerations for clinical development}

In this report, we described specific cellular biology characteristics of the S1R, which demonstrated its unique mode of action and its role as an intracellular signal modulatory system. Accumulating evidence highlights the preclinical efficacy of selective drugs targeting the S1R and acting as agonists, i.e., able to specifically activate S1R protein. Cellular data are also accumulating, allowing the clear definition of an agonist or antagonist activity at S1R. Cellular activity tests, and particularly the S1R-induced potentiation of bradykinin-induced $\mathrm{Ca}^{2+}$ mobilization [26] or the agonist-induced S1R/BiP complex dissociation [23], are now being consistently used to define drug activity. Notably, the bi-phasic effect of agonists results, with high doses of agonists, in an apparent antagonist effect of drugs, and part of the past confusion between agonist and antagonist activity at S1R is related to improper dose range of the tested compounds.

S1R agonists are good candidates for clinical development. Some drugs already in clinical use are shown to act partly through their S1R agonist activity. This is the case of fabomotizole (Afobasole ${ }^{\circledR}$ ) in anxiety [154]; fluvoxamine (Floxyfral ${ }^{\circledR}$ ) in depression [155-157]; dextromethorphan-quinidine $\left(\right.$ Nuedexta $\left.^{\circledR}\right)$ in pseudo-bulbar affect $[158,159]$; or donepezil $\left(\right.$ Aricept $\left.^{\circledR}\right)$ in $A D[56,160]$. Some other drugs are currently in clinical development and have reached phases II or III with very promising results. This is the case of blarcamesine in AD [NCT02244541, NCT04314934], PD with dementia [NCT03774459], and Rett syndrome 
[NCT04304482, NCT03941444, NCT03758924]; deudextromethorphan-quinidine (AVP-786) in AD-related agitation [NCT03393520]; bupropion-dextromethorphan (AXS-05) in major depression [NCT04039022, NCT04019704]; and pridopidine, which appears to be the most selective S1R agonist developed so far, in HD (Table 2) and ALS.

S1R drugs, by activating a cellular modulatory system, present few side-effects related to the target itself. ADME parameters, off-targets and target engagement must be assessed. An important issue remains the adequate concentration or dose of the ligand required to induce an optimal effect. The effective dose selection relies on numerous interacting factors related to the pathology, patient history and dosage form. In the case of S1R drugs, the target itself is an additional factor. Among clinical trials reported so far, igmesine was found effective at low dose of $25 \mathrm{mg}$ oral daily in depression [117]; blarcamesine was used in AD trial at doses of $30-50 \mathrm{mg}$ oral daily [161]; and pridopidine $45 \mathrm{mg}$ bid shows most beneficial effects in HD patients [NCT02006472]. These observations show at the clinical level that the definition of the optimal active dose for a S1R agonist must be carefully addressed. Determining the most adequate effective dose in patients is essential for assessing the optimal therapeutic efficacy of the S1R compounds in neurodegenerative diseases.

\section{Expert opinion}

The nature and function of S1R protein has long been elusive and controversial. The S1R was first identified as a pharmacological receptor which drew some confusion and mixed interest. The confusion was fostered by the fact that the S1R is expressed in numerous cell types and its cellular localization is not restricted. Furthermore, the S1R is reported to bind to a wide and diverse set of ligands. Its dependency on G-proteins was not clearly explained. The bellshaped concentration- or dose-response effect which was observed in cellular models or in vivo or ex vivo responses did not follow the conventional and familiar sigmoidal curves. The gene and protein have now been cloned and identified, and knowledge on the cellular biology of S1R and its role in physiopathology has greatly advanced. It appears now that the particular 
nature of S1R, suspected very early after its identification, in the early 1990 years, corresponds indeed to the cellular nature of the protein and its involvement in several cellular pathways.

Some questions remain regarding the proposed cristallographic structure of S1R, done using micelles that remain an artificial model far from physiological reality. Indeed, the data [162] mainly observed S1R as a proteic trimer with one single transmembrane domain and suggested that the C-terminal of the protein is cytosolic. On the contrary, the amount of available biochemical data showed, particularly using covalent binding and mutagenesis experiments, the presence of two transmembrane domains, the C-terminal part actually in the ER lumen [163], and homomerisation as dimers and tetramers. This research therefore still requests more investigation, particularly by including novel cristallographic models with different ligands. When considering the past studies in the field, numerous data were generated in the 1980-2000 years, using radioligand binding techniques, that particularly outlined the diversity of ligand interactions with S1R. Cristallographic approaches, which have been particularly tricky with this membrane-bound protein, will surely confirm the diverse and complex modes of pharmacodynamic interactions of S1R ligands with their target.

In other aspects, knowledge generated in the different laboratories has considerably improved our understanding of the S1R nature and function. They coherently suggested that S1R must be seen as an intracellular chaperone, although the modulation of its activity by agonists, antagonists, or positive or negative allosteric modulators, still confers some receptorlike pharmacological properties. Moreover, although its concentrated presence at MAM suggested a primary role in the facilitation of the ER-mitochondria dialog, it is also found at other cellular locations where it may interact with numerous types of substrates. Physiological signals as well as putative "endogenous ligands" (steroids, trace amines, or choline) trigger $\mathrm{S} 1 \mathrm{R}$ activation and the physiological consequence may directly depend on the S1R location and the precise signaling pathways activated. Moreover, recent discoveries on the pathological consequences of spliced and mutated S1R variants outlined its modulatory but important role on cellular homeostasis. 
S1R has been involved, through modulation of its expression or its activation/inactivation by ligands, in neurodegenerative diseases, as detailed in the present review, but also in addiction, epilepsy, pain, several forms of cancers and, very recently, viral infection particularly by SARS-Cov2 [164]. This variety of actions is not only due to the variety of signaling pathways that S1R activity regulates but also to the very fundamental pathways concerned. Indeed, the ER-mitochondria dialog for instance largely regulated by MAMs functions is crucial in $\mathrm{Ca}^{2+}$ homeostasis, regulation of mitochondrial integrity and ATP formation but also in more specific cellular responses like the formation of neuroinflammasome or autophagosome [35]. Moreover, MAMs concentrate hundreds of proteins, some of them directly responsible of pathological processes, like presenilins in $A D$, huntingtin in $H D, \alpha-$ synuclein or parkin in PD. It is therefore explaining a posteriori the diversity of actions induced by S1R drugs in physiopathology. It can be expected that novel cellular mechanisms of action will be uncovered for S1R proteins, leading to novel potential indications for S1R drugs. As basic knowldedge is presently accumulating, the therapeutic development of S1R drugs is expected to considerably expand in the near future.

Finally, mutation of MAM proteins could provoke pathological cellular degeneration, as observed for mutated S1R in juvenile forms of ALS or for mutated wolframine in Wolfram syndrome a rare genetic disease in infants with invalidating symptoms such as diabetes, blindness and deafness [35]. These observations opened new avenues for selective and effective S1R ligands in numerous therapeutic indications. Agonists are in clinical development in several neurodegenerative diseases, and we particularly pointed out the potentialities of pridopidine in this review, but also other pathologies such as epilepsy, while antagonists are developed in different pain indications and cancers.

An unsolved question remains to determine whether the high concentration of $S 1 R$ in MAMs is fundamental for the pharmacological activity of the drugs or if other, unexplored, functions of S1R are involved. S1R has been recently proposed to act as a "molecular sponge" chaperoning numerous substrates (proteins, small molecules, phospholipids, RNAs...) and may likely interfere with numerous mechanisms. Therefore, although a preferential localization 
at MAM, known to be involved in almost all neurodegenerative pathologies [35], is already an argument to explain the diversity of S1R cellular actions, it has to be further explored at the cellular level and in physiopathological models.

A second interesting aspect is that S1R ligands will act intracellularly on a basically modulatory system affecting $\mathrm{Ca}^{2+}$ homeostasis or signaling pathways that therefore could be used in combination with a more classic therapeutic drug targeting a transmembrane receptor. The resulting synergy, expected by mixing an effector drug and a modulatory S1R ligand, have already been observed in $A D$ with the acetylcholinesterase inhibitor donepezil. It deserves to be further investigated. S1R ligands tested in clinical trials so far showed a very good safety and tolerability suggesting that the target does not cause side effects by itself. S1R-based combinatory therapies may therefore not only identify new therapeutic strategies and boost the pharmacological primary action of combinatory drugs, but also allow to markedly decrease the occurrence of adverse side-effects in chronic indications.

Finally, the present review pointed out the systematic bi-phasic dose-response effects of S1R drugs and detailed putative mechanisms of action that established this hormesis as an intrinsic nature of the protein. It has two consequences on clinical development. The first is to suggest that the highest dose is not the better for S1R drugs and that, in case of lack of efficacy, lower doses must be investigated in priority. The second is that an effective biomarker must be defined during clinical trials in order to adjust the most effective dose. For instance, Hampel et al. [161] recently described that patients with S1R wildtype phenotype and high blarcamesine plasma concentration after IV administration showed the best stabilization of ADCS-ADL and MMSE scores after 162 weeks of barcamesine. No association with more classical biomarkers has been proposed yet. But this is a fundamental need and fascinating research area for the coming times, as the importance and interest for the physiopathological role of S1R and therapeutic development of S1R drugs gradually swell. 


\section{Acknowledgements}

This work was funded by INSERM. The author warmly thanks Drs Michal Geva (Prilenia, Herzliya, Israel), Michael Hayden (Prilenia, Herzliya, Israel), and Benjamin Delprat (MMDN, Montpellier, France) for advices, critical reading and inputs in the manuscript.

\section{Highlights}

- The Sigma-1 receptor (S1R) is an molecular chaperone regulating several cellular pathways in neurons and glial cells.

- S1R agonists are promising neuroprotectants in neurodegenerative diseases.

- Among them, pridopidine is a highly selective S1R agonist and showed efficacy in AD, HD and ALS preclinical models.

- All S1R responses from cellular to in vivo levels display bi-phasic curves, with low doses of ligands showing maximal effects.

- Possible mechanisms for bi-phasic effect rely on S1R dynamics including oligomerization, cellular translocation and BDNF releasing properties. 


\section{References}

1. Corriveau RA, Bosetti F, Emr M, et al. The science of vascular contributions to cognitive impairment and dementia (VCID): a framework for advancing research priorities in the cerebrovascular biology of cognitive decline. Cell Mol Neurobiol. 2016;36:281-8.

2. Selkoe DJ. Cell biology of protein misfolding: the examples of Alzheimer's and Parkinson's diseases. Nat Cell Biol. 2004;6:1054-61.

3. Coleman PD, Mastroeni D. A call for new approaches to Alzheimer's disease research Neurobiol Aging. 2017;57:iii-iv.

4. Huang LK, Chao SP, Hu CJ. Clinical trials of new drugs for Alzheimer disease. J Biomed Sci. 2020;27:18.

5. de Lau LM, Breteler MM. Epidemiology of Parkinson's disease. Lancet Neurol. 2006;5:525-35.

6. Sveinbjornsdottir S. The clinical symptoms of Parkinson's disease. J Neurochem. 2016;139 Suppl 1:318-324.

7. Braak H, Ghebremedhin E, Rüb U, Bratzke H, Del Tredici K. Stages in the development of Parkinson's disease-related pathology. Cell Tissue Res. 2004;318:121-34.

8. Logroscino G, Traynor BJ, Hardiman O, et al. Incidence of amyotrophic lateral sclerosis in Europe. J Neurol Neurosurg Psychiatry. 2010;81:385-90.

9. Dharmadasa T, Kiernan MC. Riluzole, disease stage and survival in ALS. Lancet Neurol. 2018;17:385-386.

10. Nagase M, Yamamoto $\mathrm{Y}$, Miyazaki Y, Yoshino H. Increased oxidative stress in patients with amyotrophic lateral sclerosis and the effect of edaravone administration. Redox Rep. 2016;21:104-12.

11. Forbes RB, Colville S, Swingler RJ; Scottish ALS/MND Register. The epidemiology of amyotrophic lateral sclerosis (ALS/MND) in people aged 80 or over. Age Ageing. 2004;33:131-4. 
12. Dorsey ER, Beck CA, Darwin K, et al. Natural history of Huntington disease. JAMA Neurol. 2013;70:1520-30.

13. Gil JM, Rego AC. Mechanisms of neurodegeneration in Huntington's disease. Eur J Neurosci. 2008;27:2803-20.

14. Reijonen S, Putkonen N, Nørremølle A, Lindholm D, Korhonen L. Inhibition of endoplasmic reticulum stress counteracts neuronal cell death and protein aggregation caused by N-terminal mutant huntingtin proteins. Exp Cell Res. 2008;314:950-60.

15. Reijonen S, Kukkonen JP, Hyrskyluoto A, et al. Downregulation of NF-kappaB signaling by mutant huntingtin proteins induces oxidative stress and cell death. Cell Mol Life Sci. 2010;67:1929-41.

16. Kumar A, Kumar V, Singh K, et al. Therapeutic advances for Huntington's disease. Brain Sci. 2020;10. pii: E43.

17. Crews L, Masliah E. Molecular mechanisms of neurodegeneration in Alzheimer's disease. Hum Mol Genet. 2010;19(R1):R12-R20.

18. McAvoy K, Kawamata H. Glial mitochondrial function and dysfunction in health and neurodegeneration. Mol Cell Neurosci. 2019;101:103417.

19. Angelova PR, Esteras N, Abramov AY. Mitochondria and lipid peroxidation in the mechanism of neurodegeneration: Finding ways for prevention. Med Res Rev. 2020; in press.

20. Su TP, London ED, Jaffe JH. Steroid binding at sigma receptors suggests a link between endocrine, nervous, and immune systems. Science. 1988;240:219-21.

21. Fontanilla D, Johannessen M, Hajipour AR, Cozzi NV, Jackson MB, Ruoho AE. The hallucinogen $\mathrm{N}, \mathrm{N}$-dimethyltryptamine (DMT) is an endogenous sigma-1 receptor regulator. Science. 2009;323:934-7.

22. Brailoiu E, Chakraborty S, Brailoiu GC, Zhao P, Barr JL, llies MA, Unterwald EM, Abood ME, Taylor CW. Choline Is an Intracellular Messenger Linking Extracellular Stimuli to IP3-Evoked Ca2+ Signals through Sigma-1 Receptors. Cell Rep. 2019;26:330-337.e4. 
23. Hayashi T, Su TP. Sigma-1 receptor chaperones at the ER-mitochondrion interface regulate $\mathrm{Ca}^{2+}$ signaling and cell survival. Cell. 2007;131:596-610.

- This article describes the discovery of the chaperone activity of S1R in cells and its role in the regulation of ER-mitochondrial interorganellar $\mathrm{Ca}^{2+}$ signaling and cell survival.

24. Meunier J, Hayashi T. Sigma-1 receptors regulate Bcl-2 expression by reactive oxygen species-dependent transcriptional regulation of nuclear factor kappaB. J Pharmacol Exp Ther. 2010;332:388-97.

25. Hayashi T, Maurice T, Su TP. $\mathrm{Ca}^{2+}$ signaling via sigma ${ }_{1}$-receptors: novel regulatory mechanism affecting intracellular $\mathrm{Ca}^{2+}$ concentration. J Pharmacol Exp Ther. 2000;293:788-98.

26. Goguadze N, Zhuravliova E, Morin D, Mikeladze D, Maurice T. Sigma-1 receptor agonists induce oxidative stress in mitochondria and enhance complex I activity in physiological condition, but protect against pathological oxidative stress. Neurotox Res. 2019;35:1-18.

- This article shows that S1R activity generates a physiological oxidative signal in mitochondria and ROS generation follows a bi-phasic response curve.

27. Tsai SY, Chuang JY, Tsai MS, et al. Sigma-1 receptor mediates cocaine-induced transcriptional regulation by recruiting chromatin-remodeling factors at the nuclear envelope. Proc Natl Acad Sci USA. 2015;112:E6562-70.

28. Arun AS, Eddings CR, Wilson KL. Novel missense alleles of SIGMAR1 as tools to understand emerin-dependent gene silencing in response to cocaine. Exp Biol Med (Maywood). 2019;244:1354-1361.

29. Hayashi T, Tsai SY, Mori T, Fujimoto M, Su TP. Targeting ligand-operated chaperone sigma-1 receptors in the treatment of neuropsychiatric disorders. Expert Opin Ther Targets. 2011;15:557-77.

30. Maurice T, Goguadze N. Sigma-1 $\left(\sigma_{1}\right)$ Receptor in Memory and Neurodegenerative Diseases. Handb Exp Pharmacol. 2017; 244:81-108. 
31. Benarroch EE. Sigma-1 receptor and amyotrophic lateral sclerosis. Neurology 2018;91:743-747.

32. Vavers E, Zvejniece L, Maurice T, Dambrova M. Allosteric modulators of sigma-1 receptor: a review. Front Pharmacol. 2019;10:223.

34. Ryskamp D, Wu L, Wu J, et al. Pridopidine stabilizes mushroom spines in mouse models of Alzheimer's disease by acting on the sigma-1 receptor. Neurobiol Dis. 2019;124:489-504.

34. Yang K, Wang C, Sun T. The roles of intracellular chaperone proteins, sigma receptors, in Parkinson's disease (PD) and major depressive disorder (MDD). Front Pharmacol. 2019;10:528.

35. Delprat B, Crouzier L, Su TP, Maurice T. At the crossing of ER stress and MAMs: a key role of sigma-1 receptor? Adv Exp Med Biol. 2020;1131:699-718.

36. Hampel H, Afshar M, Parmentier F, et al. Longitudinal 148-Week Update of ANAVEX ${ }^{\circledR}$ 2-73 Phase 2a Alzheimer's Disease Extension Study. J Prev Alzh Dis. 2018;5:S43.

37. Schneider LS, Thomas RG, Hendrix S, et al. Safety and efficacy of edonerpic maleate for patients with mild to moderate Alzheimer disease: a phase 2 randomized clinical trial. JAMA Neurol. 2019 Jul 8.

38. McCallister E. Lessons from Healey als on how to build platform trials quickly. BioCentury 2019; 303490.

39. Reilmann R, McGarry A, Grachev ID, et al. Safety and efficacy of pridopidine in patients with Huntington's disease (PRIDE-HD): a phase 2, randomised, placebo-controlled, multicentre, dose-ranging study. Lancet Neurol. 2019;18:165-176.

40. Su TP. Non-canonical targets mediating the action of drugs of abuse: cocaine at the sigma-1 receptor as an example. Front Neurosci. 2019;13:761.

41. Paillusson S, Stoica R, Gomez-Suaga $P$, et al. There's something wrong with my MAM; the ER-mitochondria axis and neurodegenerative diseases. Trends Neurosci. 2016;39:146-157. 
42. Rodríguez-Arribas M, Yakhine-Diop SMS, Pedro JMB, et al. Mitochondria-associated membranes (MAMs): overview and its role in Parkinson's disease. Mol Neurobiol. 2017;54:6287-303.

43. Hedskog L, Pinho CM, Filadi R, et al. Modulation of the endoplasmic. reticulummitochondria interface in Alzheimer's disease and related models. Proc Natl Acad Sci USA. 2013;110:7916-21.

44. Area-Gomez E, Del Carmen Lara Castillo M, et al. Upregulated function of mitochondria-associated ER membranes in Alzheimer disease. EMBO J. 2012;31:4106-23.

45. Liu CC, Liu CC, Kanekiyo T, Xu H, Bu G. Apolipoprotein E and Alzheimer disease: risk, mechanisms and therapy. Nat Rev Neurol. 2013;9:106-18.

46. Guardia-Laguarta C, Area-Gomez E, Rüb C, et al. a-Synuclein is localized to mitochondria-associated ER membranes. J Neurosci. 2014;34:249-59.

47. Panov AV, Gutekunst CA, Leavitt BR, et al. Early mitochondrial calcium defects in Huntington's disease are a direct effect of polyglutamines. Nat Neurosci. 2002;5:7316.

48. Atwal RS, Xia J, Pinchev D, Taylor J, Epand RM, Truant R. Huntingtin has a membrane association signal that can modulate huntingtin aggregation, nuclear entry and toxicity. Hum Mol Genet. 2007;16:2600-15.

49. Stoica R, De Vos KJ, Paillusson S, et al. ER-mitochondria associations are regulated by the VAPB-PTPIP51 interaction and are disrupted by ALS/FTD-associated TDP-43. Nat Commun. 2014;5:3996.

50. Khalil B, Cabirol-Pol MJ, Miguel L, Whitworth AJ, Lecourtois M, Liévens JC. Enhancing Mitofusin/Marf ameliorates neuromuscular dysfunction in Drosophila models of TDP43 proteinopathies. Neurobiol Aging. 2017;54:71-83.

51. Mháille AN, McQuaid S, Windebank A, et al. Increased expression of endoplasmic reticulum stress-related signaling pathway molecules in multiple sclerosis lesions. J Neuropathol Exp Neurol. 2008;67:200-11. 
52. Haile Y, Deng X, Ortiz-Sandoval C, et al. Rab32 connects ER stress to mitochondrial defects in multiple sclerosis. J Neuroinflammation. 2017;14:19.

53. Marrazzo A, Caraci F, Salinaro ET, Su TP, Copani A, Ronsisvalle G. Neuroprotective effects of sigma-1 receptor agonists against beta-amyloid-induced toxicity. Neuroreport. 2005;16:1223-6.

54. Behensky AA, Yasny IE, Shuster AM, Seredenin SB, Petrov AV, Cuevas J. Afobazole activation of $\sigma-1$ receptors modulates neuronal responses to amyloid- $\beta_{25-35}$. J Pharmacol Exp Ther. 2013;347:468-77.

55. Behensky AA, Yasny IE, Shuster AM, Seredenin SB, Petrov AV, Cuevas J. Stimulation of sigma receptors with afobazole blocks activation of microglia and reduces toxicity caused by amyloid- $\beta_{25-35}$. J Pharmacol Exp Ther. 2013;347:458-67.

56. Meunier J, leni J, Maurice T. The anti-amnesic and neuroprotective effects of donepezil against amyloid $\beta_{25-35}$ peptide-induced toxicity in mice involve an interaction with the $\sigma 1$ receptor. Br J Pharmacol. 2006;149:998-1012.

57. Villard V, Espallergues J, Keller E, et al. Antiamnesic and neuroprotective effects of the aminotetrahydrofuran derivative ANAVEX1-41 against amyloid $\beta_{25-35}$-induced toxicity in mice. Neuropsychopharmacology. 2009;34:1552-66.

- This article shows that the neuroprotective activity of a high affinity S1R agonist in a pharmacological mouse model of $A D$ follows a bi-phasic response curve in vivo.

58. Villard V, Espallergues J, Keller E, Vamvakides A, Maurice T. Anti-amnesic and neuroprotective potentials of the mixed muscarinic receptor/sigma $1\left(\sigma_{1}\right)$ ligand ANAVEX2-73, a novel aminotetrahydrofuran derivative. J. Psychopharmacol. 2011;25:1101-17.

59. Aly HF, Metwally FM, Ahmed HH. Neuroprotective effects of dehydroepiandrosterone (DHEA) in rat model of Alzheimer's disease. Acta Biochim Pol. 2011;58:513-20. 
60. Antonini V, Marrazzo A, Kleiner G, et al. Anti-amnesic and neuroprotective actions of the sigma-1 receptor agonist (-)-MR22 in rats with selective cholinergic lesion and amyloid infusion. J Alzheimers Dis. 2011;24:569-86.

61. Yang R, Chen L, Wang H, Xu B, Tomimoto H, Chen L. Anti-amnesic effect of neurosteroid PREGS in $A \beta_{25-35}$-injected mice through $\sigma_{1}$ receptor- and $\alpha_{7} \mathrm{nAChR}$ mediated neuroprotection. Neuropharmacology. 2012;63:1042-50.

62. Lahmy V, Meunier J, Malmström S, et al. Blockade of Tau hyperphosphorylation and $A \beta_{1-42}$ generation by the aminotetrahydrofuran derivative ANAVEX2-73, a mixed muscarinic and $\sigma_{1}$ receptor agonist, in a nontransgenic mouse model of Alzheimer's disease. Neuropsychopharmacology. 2013;38:1706-23.

63. Fisher A, Bezprozvanny I, Wu L, et al. AF710B, a novel M1/ $\sigma_{1}$ agonist with therapeutic efficacy in animal models of Alzheimer's disease. Neurodegener Dis. 2016;16:95-110.

64. Hall H, lulita MF, Gubert P, et al. AF710B, an M1/sigma-1 receptor agonist with longlasting disease-modifying properties in a transgenic rat model of Alzheimer's disease. Alzheimers Dement. 2018;14:811-823.

65. Christ MG, Huesmann H, Nagel H, Kern A, Behl C. Sigma-1 receptor activation induces autophagy and increases proteostasis capacity in vitro and in vivo. Cells. 2019;8. pii: E211.

66. Francardo V, Bez F, Wieloch T, Nissbrandt H, Ruscher K, Cenci MA. Pharmacological stimulation of sigma-1 receptors has neurorestorative effects in experimental parkinsonism. Brain. 2014;137:1998-2014.

67. Francardo V, Geva M, Bez F, et al. pridopidine induces functional neurorestoration via the sigma-1 receptor in a mouse model of Parkinson's disease. Neurotherapeutics. 2019;16:465-479.

68. Voronin MV, Kadnikov IA, Voronkov DN, Seredenin SB. Chaperone Sigma1R mediates the neuroprotective action of afobazole in the 6-OHDA model of Parkinson's disease. Sci Rep. 2019;9:17020 
69. Guo CH, Cao T, Zheng LT, Waddington JL, Zhen XC. Development and characterization of an inducible Dicer conditional knockout mouse model of Parkinson's disease: validation of the antiparkinsonian effects of a sigma-1 receptor agonist and dihydromyricetin. Acta Pharmacol Sin. 2020;41:499-507.

70. Al-Saif A, Al-Mohanna F, Bohlega S. A mutation in sigma-1 receptor causes juvenile amyotrophic lateral sclerosis. Ann Neurol. 2011;70:913-9.

71. Watanabe $\mathrm{S}$, llieva $\mathrm{H}$, Tamada $\mathrm{H}$, et al. Mitochondria-associated membrane collapse is a common pathomechanism in SIGMAR1- and SOD1-linked ALS. EMBO Mol Med. 2016;8:1421-37.

72. Izumi $\mathrm{Y}$, Morino $\mathrm{H}$, Miyamoto $\mathrm{R}$, et al. Compound heterozygote mutations in the SIGMAR1 gene in an oldest-old patient with amyotrophic lateral sclerosis. Geriatr Gerontol Int. 2018;18:1519-1520.

73. Couly S, Khalil B, Viguier V, Roussel J, Maurice T, Liévens JC. Sigma-1 receptor is a key genetic modulator in amyotrophic lateral sclerosis. Hum Mol Genet. 2019. pii: ddz267.

74. Mavlyutov TA, Epstein ML, Verbny YI, et al. Lack of sigma-1 receptor exacerbates ALS progression in mice. Neuroscience. 2013;240:129-34.

75. Mancuso R, Oliván S, Rando A, Casas C, Osta R, Navarro X. Sigma-1R agonist improves motor function and motoneuron survival in ALS mice. Neurotherapeutics. 2012;9:814-26

76. Ono $\mathrm{Y}$, Tanaka H, Takata M, et al. SA4503, a sigma-1 receptor agonist, suppresses motor neuron damage in in vitro and in vivo amyotrophic lateral sclerosis models. Neurosci Lett. 2014;559:174-8.

77. Peviani M, Salvaneschi E, Bontempi L, et al. Neuroprotective effects of the Sigma-1 receptor (S1R) agonist PRE-084, in a mouse model of motor neuron disease not linked to SOD1 mutation. Neurobiol Dis. 2014;62:218-32. 
78. Hyrskyluoto A, Pulli I, Törnqvist K, Ho TH, Korhonen L, Lindholm D. Sigma-1 receptor agonist PRE084 is protective against mutant huntingtin-induced cell degeneration: involvement of calpastatin and the NF-KB pathway. Cell Death Dis. 2013;4:e646.

79. Miki Y, Tanji K, Mori F, Wakabayashi K. Sigma-1 receptor is involved in degradation of intranuclear inclusions in a cellular model of Huntington's disease. Neurobiol Dis. 2015;74:25-31.

80. Pettersson F, Pontén H, Waters N, Waters S, Sonesson C. Synthesis and evaluation of a set of 4-phenylpiperidines and 4-phenylpiperazines as D2 receptor ligands and the discovery of the dopaminergic stabilizer 4-[3-(methylsulfonyl)phenyl]-1propylpiperidine (huntexil, pridopidine, ACR16). J Med Chem. 2010;53:2510-20.

81. Sahlholm K, Århem P, Fuxe K, Marcellino D. The dopamine stabilizers ACR16 and (-)OSU6162 display nanomolar affinities at the $\sigma-1$ receptor. Mol Psychiatry. 2013;18:124.

82. Johnston $\mathrm{TH}$, Geva M, Steiner L, et al. Pridopidine, a clinic-ready compound, reduces 3,4-dihydroxyphenylalanine-induced dyskinesia in Parkinsonian macaques. Mov Disord. 2019;34:708-716.

83. Sahlholm K, Sijbesma JW, Maas B, et al. Pridopidine selectively occupies sigma-1 rather than dopamine D2 receptors at behaviorally active doses. Psychopharmacology (Berl). 2015;232:3443-53.

84. Ionescu A, Gradus T, Altman T, et al. Targeting the sigma-1 receptor via pridopidine ameliorates central features of ALS pathology in a SOD1 ${ }^{\mathrm{G} 93 \mathrm{~A}}$ model. Cell Death Dis. $2019 ; 10: 210$.

85. Squitieri F, Di Pardo A, Favellato M, Amico E, Maglione V, Frati L. Pridopidine, a dopamine stabilizer, improves motor performance and shows neuroprotective effects in Huntington disease R6/2 mouse model. J Cell Mol Med. 2015;19:2540-8.

86. Geva M, Kusko R, Soares $\mathrm{H}$, et al. Pridopidine activates neuroprotective pathways impaired in Huntington disease. Hum Mol Genet. 2016;25:3975-3987. 
87. Garcia-Miralles M, Geva M, Tan JY, et al. Early pridopidine treatment improves behavioral and transcriptional deficits in YAC128 Huntington disease mice. JCI Insight. 2017;2:pii: 95665.

88. Eddings CR, Arbez N, Akimov S, Geva M, Hayden MR, Ross CA. Pridopidine protects neurons from mutant-huntingtin toxicity via the sigma-1 receptor. Neurobiol Dis. 2019;129:118-129.

89. Smith-Dijak AI, Nassrallah WB, Zhang LYJ, Geva M, Hayden MR, Raymond LA. Impairment and restoration of homeostatic plasticity in cultured cortical neurons from a mouse model of Huntington disease. Front Cell Neurosci. 2019;13:209.

90. Calabrese EJ, Baldwin LA. Hormesis: a generalizable and unifying hypothesis. Crit Rev Toxicol. 2001;31:353-424.

91. Calabrese EJ, Baldwin LA. Defining hormesis. Hum Exp Toxicol. 2002;21:91-7.

92. Calabrese EJ. Neuroscience and hormesis: overview and general findings. Crit Rev Toxicol. 2008;38:249-52.

93. Calabrese EJ. Hormesis and medicine. Br J Clin Pharmacol. 2008;66:594-617.

- This article provides a very informative review on hormesis in the pharmacological effects of druigs in several indications from neurology to peripheral organs diseases.

94. Roman, FJ, Pascaud X, Duffy O, Junien JL. Modulation by neuropeptide $\mathrm{Y}$ and peptide YY of NMDA effects in hippocampal slices: role of $\sigma_{1}$ receptors. In: NMDA Related Agents: Biochemistry, Pharmacology and Behavior. Kameyama T, Nabeshima T, Domino EF, Eds. NPP Books, Ann Arbor, 1991; 211-8.

95. Monnet FP, Blier P, Debonnel G, de Montigny C. Modulation by sigma ligands of Nmethyl-D-aspartate-induced $\left[{ }^{3} \mathrm{H}\right]$ noradrenaline release in the rat hippocampus: Gprotein dependency. Naunyn Schmiedebergs Arch Pharmacol. 1992;346:32-9.

- This article describes the NMDAR-potentiating effect of S1R agonists on norepinephrine release and the first observation of the S1R bi-phasic effect. 
96. Monnet FP, Debonnel G, Junien JL, De Montigny C. N-methyl-D-aspartate-induced neuronal activation is selectively modulated by $\sigma_{1}$ receptors. Eur $\mathrm{J}$ Pharmacol. 1990;179:441-5

97. Monnet FP, Debonnel G, De Montigny C. In vivo electrophysiological evidence for a selective modulation of $\mathrm{N}$-methyl-D-aspartate-induced neuronal activation in rat CA3 dorsal hippocampus by $\sigma_{1}$ ligands, J Pharmacol Exp Ther 1992;261:123-30.

98. Bergeron R, de Montigny C, Debonnel G. Biphasic effects of sigma ligands on the neuronal response to N-methyl-D-aspartate. Naunyn Schmiedebergs Arch Pharmacol. $1995 ; 351: 252-60$.

99. Monnet FP, de Costa BR, Bowen WD. Differentiation of sigma ligand-activated receptor subtypes that modulate NMDA-evoked $\left[{ }^{3} \mathrm{H}\right]$-noradrenaline release in rat hippocampal slices. Br J Pharmacol. 1996;119:65-72.

100. Bermack JE, Debonnel G. The role of sigma receptors in depression. J Pharmacol Sci. 2005;97:317-36.

101. Bergeron R, Debonnel G. Effects of low and high doses of selective sigma ligands: further evidence suggesting the existence of different subtypes of sigma receptors. Psychopharmacology (Berl). 1997;129:215-24.

102. McLarnon J, Sawyer D, Church J. The actions of L-687,384, a sigma receptor ligand, on NMDA-induced currents in cultured rat hippocampal pyramidal neurons. Neurosci Lett. $1994 ; 174: 181-4$.

103. Lucas G, Rymar VV, Sadikot AF, Debonnel G. Further evidence for an antidepressant potential of the selective sigma1 agonist SA 4503: electrophysiological, morphological and behavioural studies. Int J Neuropsychopharmacol. 2008;11:485-95.

104. Peeters M, Romieu P, Maurice T, Su TP, Maloteaux JM, Hermans E. Involvement of the sigma ${ }_{1}$ receptor in the modulation of dopaminergic transmission by amantadine. Eur J Neurosci. 2004;19:2212-20. 
105. Maurice T, Hiramatsu M, Itoh J, Kameyama T, Hasegawa T, Nabeshima T. Low dose of 1,3-di(2-tolyl)guanidine (DTG) attenuates MK-801-induced spatial working memory impairment in mice. Psychopharmacology (Berl). 1994;114:520-2.

106. Maurice T, Hiramatsu M, Itoh J, Kameyama T, Hasegawa T, Nabeshima T. Behavioral evidence for a modulating role of sigma ligands in memory processes. I. Attenuation of dizocilpine (MK-801)-induced amnesia. Brain Res. 1994;647:44-56.

107. Maurice T, Su TP, Parish DW, Nabeshima T, Privat A. PRE-084, a sigma selective PCP derivative, attenuates MK-801-induced impairment of learning in mice. Pharmacol Biochem Behav. 1994;49:859-69.

108. Maurice T, Privat A. SA4503, a novel cognitive enhancer with sigma 1 receptor agonist properties, facilitates NMDA receptor-dependent learning in mice. Eur J Pharmacol. 1997;328:9-18

109. Senda T, Matsuno K, Okamoto K, Kobayashi T, Nakata K, Mita S. Ameliorating effect of SA4503, a novel sigma 1 receptor agonist, on memory impairments induced by cholinergic dysfunction in rats. Eur J Pharmacol. 1996;315:1-10.

110. Espallergues J, Lapalud, $\mathrm{P}$, Christopoulos A, et al. Involvement of the sigma1 $\left(\sigma_{1}\right)$ receptor in the anti-amnesic, but not antidepressant-like, effects of the aminotetrahydrofuran derivative ANAVEX1-41. Br J Pharmacol. 2007; 152:267-79.

111. Maurice T, Roman FJ, Su TP, Privat A. Beneficial effects of sigma agonists on the agerelated learning impairment in the senescence-accelerated mouse (SAM). Brain Res. $1996 ; 733: 219-30$.

112. Senda T, Matsuno K, Kobayashi T, Nakazawa M, Nakata K, Mita S. Ameliorative effect of SA4503, a novel cognitive enhancer, on the basal forebrain lesion-induced impairment of the spatial learning performance in rats. Pharmacol Biochem Behav. $1998 ; 59: 129-34$

113. Maurice T, Su TP, Privat A. Sigma ${ }_{1}\left(\sigma_{1}\right)$ receptor agonists and neurosteroids attenuate $\beta_{25-35}$-amyloid peptide-induced amnesia in mice through a common mechanism. Neuroscience. 1998;83:413-28. 
114. Zvejniece L, Vavers E, Svalbe B, et al. The cognition-enhancing activity of E1R, a novel positive allosteric modulator of sigma-1 receptors. Br J Pharmacol. 2014;171:761-71.

115. Maurice T, Volle JN, Strehaiano M, et al. Neuroprotection in non-transgenic and transgenic mouse models of Alzheimer's disease by positive modulation of $\sigma_{1}$ receptors. Pharmacol Res. 2019;144:315-330.

116. Martin P, de Witte PAM, Maurice T, et al. Fenfluramine acts as a positive modulator of sigma-1 receptors. Epilep Behav. 2020;in press.

117. Pande AC, Genève J, Scherrer B, Smith F, Leadbetter RA, de Meynard C. A placebocontrolled trial of igmesine in the treatment of major depression. Eur Neuropsychopharmacology 1999;9:S138.

118. Wilke RA, Mehta RP, Lupardus PJ, Chen Y, Ruoho AE, Jackson MB. Sigma receptor photolabeling and sigma receptor-mediated modulation of potassium channels in tumor cells. J. Biol. Chem. 1999;274:18387-92.

119. Hayashi T, Su TP. Regulating ankyrin dynamics: Roles of sigma-1 receptors. Proc Natl Acad Sci USA. 2001;98:491-6.

120. Johannessen M, Ramachandran S, Riemer L, Ramos-Serrano A, Ruoho AE, Jackson MB. Voltage-gated sodium channel modulation by sigma-receptors in cardiac myocytes and heterologous systems. Am J Physiol Cell Physiol. 2009;296:C1049-57.

121. Carnally SM, Johannessen M, Henderson RM, Jackson MB, Edwardson JM. Demonstration of a direct interaction between sigma-1 receptors and acid-sensing ion channels. Biophys. J. 2010;98:1182-1191.

122. Kim FJ, Kovalyshyn I, Burgman M, Neilan C, Chien CC, Pasternak GW. Sigma 1 receptor modulation of G-protein-coupled receptor signaling: potentiation of opioid transduction independent from receptor binding. Mol. Pharmacol. 2010;77:695-703.

123. Chu UB, Ruoho AE. Biochemical Pharmacology of the Sigma-1 Receptor. Mol Pharmacol. 2016;89:142-53. 
124. Mishra AK, Mavlyutov T, Singh DR, et al. The sigma-1 receptors are present in monomeric and oligomeric forms in living cells in the presence and absence of ligands. Biochem J. 2015;466:263-271.

125. Su TP, Su TC, Nakamura Y, Tsai SY. The Sigma-1 Receptor as a Pluripotent Modulator in Living Systems. Trends Pharmacol Sci. 2016;37:262-78.

126. Soriani O, Kourrich S. The Sigma-1 Receptor: When Adaptive Regulation of Cell Electrical Activity Contributes to Stimulant Addiction and Cancer. Front Neurosci. 2019;13:1186.

127. Hayashi T, Su TP. Sigma-1 receptors ( $\sigma_{1}$ binding sites) form raft-like microdomains and target lipid droplets on the endoplasmic reticulum: roles in endoplasmic reticulum lipid compartmentalization and export. J Pharmacol Exp Ther. 2003;306:718-25.

128. Hayashi T, Su TP. Intracellular dynamics of sigma-1 receptors ( $\sigma_{1}$ binding sites) in NG108-15 cells. J Pharmacol Exp Ther. 2003;306:726-33.

- This article described the cellular dynamics of S1R tranbslocation between ER lipid droplets and higher density membranes upon activation suggesting that it affects lipid transport and distribution in neuronal cells.

129. Meunier J, Demeilliers B, Celerier A, Maurice T. Compensatory effect by sigma ${ }_{1}\left(\sigma_{1}\right)$ receptor stimulation during alcohol withdrawal in mice performing an object recognition task. Behav Brain Res. 2006a;166:166-76.

130. Kourrich S, Hayashi T, Chuang JY, Tsai SY, Su TP, Bonci A. Dynamic interaction between sigma-1 receptor and Kv1.2 shapes neuronal and behavioral responses to cocaine. Cell. 2013;152:236-47.

131. Balasuriya D, Stewart AP, Edwardson JM. The $\sigma-1$ receptor interacts directly with GluN1 but not GluN2A in the GluN1/GluN2A NMDA receptor. J Neurosci. 2013;33:18219-24.

132. Mavlyutov TA, Duellman T, Kim HT, Epstein ML, Leese C, Davletov BA, Yang J. Sigma1 receptor expression in the dorsal root ganglion: Reexamination using a highly specific antibody. Neuroscience. 2016;331:148-57. 
133. Mavlyutov TA, Epstein M, Guo LW. Subcellular localization of the sigma-1 receptor in retinal neurons - an electron microscopy study. Sci Rep. 2015;5:10689.

134. Ovalle S, Andreu F, Pérez MP, Zamanillo D, Guitart X. Effect of the novel sigma1 receptor ligand and putative atypical antipsychotic E-5842 on BDNF mRNA expression in the rat brain. Neuroreport. 2002;13:2345-8.

135. Kikuchi-Utsumi K, Nakaki T. Chronic treatment with a selective ligand for the sigma-1 receptor chaperone, SA4503, up-regulates BDNF protein levels in the rat hippocampus. Neurosci Lett. 2008;440:19-22.

136. Fujimoto M, Hayashi T, Urfer R, Mita S, Su TP. Sigma-1 receptor chaperones regulate the secretion of brain-derived neurotrophic factor. Synapse. 2012;66:630-9.

137. Dalwadi DA, Kim S, Schetz JA. Activation of the sigma-1 receptor by haloperidol metabolites facilitates brain-derived neurotrophic factor secretion from human astroglia. Neurochem Int. 2017;105:21-31.

138. Yagasaki Y, Numakawa T, Kumamaru E, Hayashi T, Su TP, Kunugi H. Chronic antidepressants potentiate via sigma-1 receptors the brain-derived neurotrophic factorinduced signaling for glutamate release. J Biol Chem. 2006;281:12941-9.

139. Ring RM, Regan CM. Captodiamine, a putative antidepressant, enhances hypothalamic BDNF expression in vivo by synergistic $5-\mathrm{HT}_{2 \mathrm{c}}$ receptor antagonism and sigma-1 receptor agonism. J Psychopharmacol. 2013;27:930-9.

140. Mamounas LA, Blue ME, Siuciak JA, Altar CA. Brain-derived neurotrophic factor promotes the survival and sprouting of serotonergic axons in rat brain. J Neurosci. 1995;15:7929-39.

141. Mamounas LA, Altar CA, Blue ME, Kaplan DR, Tessarollo L, Lyons WE. BDNF promotes the regenerative sprouting, but not survival, of injured serotonergic axons in the adult rat brain. J Neurosci. 2000;20:771-82.

142. Boyd JG, Gordon T. A dose-dependent facilitation and inhibition of peripheral nerve regeneration by brain-derived neurotrophic factor. Eur J Neurosci. 2002;15:613-26. 
143. Xu J, Zeng C, Chu W, Pan F, Rothfuss JM, Zhang F, Tu Z, Zhou D, Zeng D, Vangveravong S, Johnston F, Spitzer D, Chang KC, Hotchkiss RS, Hawkins WG, Wheeler KT, Mach RH. Identification of the PGRMC1 protein complex as the putative sigma-2 receptor binding site. Nat Commun. 2011;2:380.

144. Alon A, Schmidt HR, Wood MD, Sahn JJ, Martin SF, Kruse AC. Identification of the gene that codes for the $\sigma_{2}$ receptor. Proc Natl Acad Sci USA. 2017;114:7160-7165.

145. Longhitano L, Castracani CC, Tibullo D, et al. Sigma-1 and Sigma-2 receptor ligands induce apoptosis and autophagy but have opposite effect on cell proliferation in uveal melanoma. Oncotarget. 2017;8:91099-91111.

146. Wei Z, Mousseau DD, Dai Y, Cao X, Li XM. Haloperidol induces apoptosis via the $\sigma_{2}$ receptor system and Bcl-XS. Pharmacogenomics J. 2006;6:279-88.

147. Katnik C, Garcia A, Behensky AA, et al. Treatment with afobazole at delayed time points following ischemic stroke improves long-term functional and histological outcomes. Neurobiol Dis. 2014;62:354-64.

148. Katnik C, Garcia A, Behensky AA, et al. Activation of $\sigma_{1}$ and $\sigma_{2}$ receptors by afobazole increases glial cell survival and prevents glial cell activation and nitrosative stress after ischemic stroke. J Neurochem. 2016;139:497-509.

149. Tesei A, Cortesi M, Zamagni A, et al. sigma receptors as endoplasmic reticulum stress "gatekeepers" and their modulators as emerging new weapons in the fight against cancer. Front Pharmacol. 2018;9:711.

150. Grundman M, Morgan R, Lickliter JD, et al. A phase 1 clinical trial of the sigma-2 receptor complex allosteric antagonist CT1812, a novel therapeutic candidate for Alzheimer's disease. Alzheimers Dement. 2019;5:20-26.

151. Yi B, Sahn JJ, Ardestani PM, et al. Small molecule modulator of sigma 2 receptor is neuroprotective and reduces cognitive deficits and neuroinflammation in experimental models of Alzheimer's disease. J Neurochem. 2017;140:561-575. 
152. Izzo NJ, Xu J, Zeng $\mathrm{C}$, et al. Alzheimer's therapeutics targeting amyloid beta 1-42 oligomers II: Sigma-2/PGRMC1 receptors mediate $A \beta_{42}$ oligomer binding and synaptotoxicity. PLoS One. 2014;9:e111899.

153. Tesei A, Cortesi M, Pignatta S, et al. Anti-tumor efficacy assessment of the sigma receptor pan modulator RC-106. A promising therapeutic tool for pancreatic cancer. Front Pharmacol. 2019;10:490.

154. Seredenin SB, Antipova TA, Voronin MV, Kurchashova SY, Kuimov AN. Interaction of afobazole with sigma1-receptors. Bull Exp Biol Med. 2009;148:42-4.

155. Narita N, Hashimoto K, Tomitaka S, Minabe Y. Interactions of selective serotonin reuptake inhibitors with subtypes of sigma receptors in rat brain. Eur $\mathrm{J}$ Pharmacol. 1996;307:117-9.

156. Takebayashi M, Hayashi T, Su TP. Nerve growth factor-induced neurite sprouting in PC12 cells involves sigma-1 receptors: implications for antidepressants. J Pharmacol Exp Ther. 2002;303:1227-37.

157. Hashimoto K, Fujita $\mathrm{Y}$, lyo M. Phencyclidine-induced cognitive deficits in mice are improved by subsequent subchronic administration of fluvoxamine: role of sigma-1 receptors. Neuropsychopharmacology. 2007;32:514-21.

158. Werling LL, Lauterbach EC, Calef U. Dextromethorphan as a potential neuroprotective agent with unique mechanisms of action. Neurologist. 2007;13:272-93.

159. Nguyen L, Robson MJ, Healy JR, Scandinaro AL, Matsumoto RR. Involvement of sigma-1 receptors in the antidepressant-like effects of dextromethorphan. PLoS One. 2014;9:e89985.

160. Maurice T, Meunier J, Feng B, leni J, Monaghan DT. Interaction with sigma ${ }_{1}$ protein, but not N-methyl-D-aspartate receptor, is involved in the pharmacological activity of donepezil. J Pharmacol Exp Ther. 2006;317:606-14.

161. Hampel $\mathrm{H}$, Williams $\mathrm{C}$, Etcheto $\mathrm{A}$, et al. A precision medicine framework using artificial intelligence for the identification and confirmation of genomic biomarkers of response 
to an Alzheimer's disease therapy: Analysis of the blarcamesine (ANAVEX2-73) Phase 2a clinical study. Alzheimers Dement (NY). 2020;6:e12013.

162. Schmidt HR, Betz RM, Dror RO, Kruse AC. Structural basis for $\sigma_{1}$ receptor ligand recognition. Nat Struct Mol Biol. 2018;25:981-987.

163. Mavylutov T, Chen X, Guo L, Yang J. APEX2- tagging of Sigma 1-receptor indicates subcellular protein topology with cytosolic $\mathrm{N}$-terminus and ER luminal C-terminus. Protein Cell 2018;9:733-7.

164. Gordon DE, Jang GM, Bouhaddou M, et al. A SARS-CoV-2 protein interaction map reveals targets for drug repurposing. Nature. 2020; 583:459-68. 
Table 1. Pridopidine binding profile and selectivity ranked in descending order of affinity (Ki) [Adapted from 82].

\begin{tabular}{lcccc}
\hline Target & I $_{50}(\boldsymbol{\mu M})$ & $\mathrm{Ki}(\boldsymbol{\mu M})$ & $\mathrm{nH}$ & Selectivity vs. S1R \\
\hline Sigma-1 (S1R) & 0.14 & 0.057 & 0.87 & - \\
Adrenergic $\mathrm{\alpha}_{2 \mathrm{C}}$ & 3.56 & 1.58 & 0.76 & $28 \mathrm{x}$ \\
Dopamine D3 & 4.79 & 1.63 & 0.90 & $29 \mathrm{x}$ \\
Serotonin 5-HT $1 \mathrm{~A}$ & 6.36 & 3.63 & 0.72 & $64 \mathrm{x}$ \\
Sigma-2 (S2R) & 7.16 & 5.45 & 0.80 & $96 \mathrm{x}$ \\
Serotonin 5-HT & $2 \mathrm{AA}$ & 7.00 & 0.81 & $123 \mathrm{x}$ \\
Serotonin 5-HT & 14.8 & 8.51 & 1.02 & $149 \mathrm{x}$ \\
Adrenergic $\mathrm{\alpha}_{2 \mathrm{~A}}$ & 22.0 & 11.0 & 0.98 & $193 \mathrm{x}$ \\
Histamine $\mathrm{H}_{3}$ & 37.6 & 18.3 & 0.85 & $321 \mathrm{x}$ \\
Muscarinic M2 & 58.1 & 24.4 & 0.62 & $428 \mathrm{x}$ \\
Dopamine D2 & 88.4 & 29.5 & 0.94 & $518 \mathrm{x}$ \\
\hline
\end{tabular}


Table 2. Pridopidine HD clinical trials.

\begin{tabular}{|c|c|c|c|c|}
\hline Study number & Title & Duration & Doses & Number of subjects \\
\hline ACR16C008 & A multi-center, multinational, randomized, double-blind, parallel- & 24 weeks & Placebo & 437 \\
\hline MermaiHD & group study comparing pridopidine $45 \mathrm{mg}$ once daily or twice & (6-months) & 45 mg QD (45 mg /day) & 144 - placebo \\
\hline (Phase 3) & daily vs. placebo for the symptomatic treatment of HD & & 45 mg BID (90 mg/day) & 293 - pridopidine \\
\hline \multicolumn{5}{|l|}{ NCT00665223 } \\
\hline ACR16C009 & A multi-center, North American, randomized, double-blind, & 12 weeks & Placebo & 227 \\
\hline HART & parallel-group study comparing three doses of ACR16 vs. & (3 months) & 10 mg BID (20 mg/day) & 58 - placebo \\
\hline (Phase 2) & placebo for the symptomatic treatment of $\mathrm{HD}$ & & 22.5 mg BID (45 mg/day) & 169 - pridopidine \\
\hline NCT00724048 & & & 45 mg BID (90 mg/day) & \\
\hline ACR16C015 & A multi-center, North American, open-label extension study of & $>5$ years & 45 mg BID (90 mg/day) & 134 \\
\hline Open-HART & pridopidine (ACR16) in the symptomatic treatment of HD & & & \\
\hline \multicolumn{5}{|l|}{ (Phase 2) } \\
\hline \multicolumn{5}{|l|}{ NCT01306929 } \\
\hline TV7820-CNS- & A phase 2, dose-finding, randomized, parallel-group, double- & 52 weeks & Placebo & 408 \\
\hline 20002 & blind, placebo-controlled study, evaluating the safety and & (12 months) & 45 mg BID (90 mg/day) & 82 - placebo \\
\hline PRIDE-HD & efficacy of pridopidine $45 \mathrm{mg}, 67.5 \mathrm{mg}, 90 \mathrm{mg}$, and $112.5 \mathrm{mg}$ & & 67.5 mg BID (135 mg/day) & 326 - pridopidine \\
\hline (Phase 2) & twice daily vs. placebo for symptomatic treatment in subjects & & 90 mg BID (180 mg/day) & \\
\hline NCT02006472 & with HD & & 112.5 mg BID (225 mg/day) & \\
\hline
\end{tabular}

Abbreviations: QD, once daily; BID, twice daily. 


\section{Legends for the figures}

Figure 1. Chemical structures of the main $S 1 R$ ligands cited in this review, distinguihing $S 1 R$ agonists, antagonists and positive modulators. The selective compounds, showing selectivity ratios $>30$ for any other target including S2R, are named in bold.

Figure 2. Typical examples of bi-phasic dose-response effects induced by S1R agonists in physiological, cellular and integrated responses.

(a) Dose-response effects of igmesine on the release of $\left[{ }^{3} \mathrm{H}\right]$ norepinephrine evoked by NMDA in rat hippocampal slice [reproduced with permission from 95]. (b) Effect of intravenously administered igmesine on the neuronal activation of CA3 dorsal hippocampus pyramidal neurons induced by microiontophoretic applications of NMDA. The drug effect was assessed by determining the ratio of the number of spikes generated/nC of NMDA before (N1) and after (N2) injection [reproduced with permission from 100]. (c) Dose-response effects of 2-day treatment with cutamesine on the firing rate of dorsal raphe nucleus (DRN) 5-HT neurons. Cutamesine (SA4503) was administered via osmotic minipumps inserted subcutaneously [reproduced with permission from 103]. (d) Potentiation of BDK-induced increase in $\left[\mathrm{Ca}^{2+}\right]_{\mathrm{cyt}}$ in NG108 cells by pregnenolone sulfate (PS), (+)-pentazocine ((+)-PTZ) and PRE-084 [reproduced with permission from 25]. (e) Concentration-response effect of PRE-084 on mitochondrial ROS level under physiological conditions in mouse forebrain mitochondria [reproduced with permission from 26]. (f) Anti-amnesic effect of PRE-084 on alternation behavior in MK-801-treated mice. PRE-084 was injected 10 min before MK-801, injected 20 min before the test [reproduced with permission from 107]. (g) Neuroprotective effect of ANAVEX1-41 on alternation behavior in the $A \beta_{25-35}$ injection mouse model of Alzheimer's disease. ANAVEX1-41 was injected 20 min after the $A \beta_{25-35}$ peptide, injected 7 days before the test [reproduced with permission from 57]. (h) Chronic treatment with PRE-084 induces neurohistological restoration in the 6-hydroxydopamine (6-OHDA) lesional mouse model of 
Parkinson's disease. Stereological counts of tyrosine hydroxylase (TH)-positive cells were performed in the substantia nigra pars compacta (SNc) [reproduced with permission from 66].

Figure 3. Putative mechanisms sustaining the bi-phasic dose-response effects of S1R agonists.

(a) S1R oligomerization [124]. [1] S1Rs can be found in monomeric and oligomeric forms in physiological conditions. Agonists favor monomers and dimers while antagonists favor oligomers. [2] At low doses, agonists activate S1R by binding to monomers or dimers and promoting its association with client proteins. [3] At high doses, agonists also bind higher order oligomers thus favoring an antagonist state and decreasing the global S1R response. (b) S1R cellular dynamics [127, 128]. [4] Rapid effects of S1R agonists are related to $\mathrm{Ca}^{2+}$ exchanges driven between the plasma membrane ionophores and MAMs. [5] Low doses of agonist potentiate $\mathrm{Ca}^{2+}$ influx and cellular response. [6] High doses of S1R agonist impact the cellular compartmentalization of S1R to an extent that counteracts the protein activity at its primary site of action. (c) S1R activity on BDNF system. [7] S1R activation enhances BDNF levels and secretion in the hippocampus and cortex [134-137]. BDNF trophic effects also demonstrate a bi-phasic dose-response curves. Low concentrations of BDNF induce a sustained activation of its high affinity TrkB receptor and trophic effect related signaling (PLC, PI3K and MEK pathways). [8] Higher concentrations of BDNF lead to activation of p75NTR, the low affinity BDNF receptor, and down-regulation of full-length TrkB isoform. p75NTR likely mediates the inhibitory effects observed at high doses of BDNF (JNK and NF-KB pathways). 
S1R agonists

Blarcamesine (ANAVEX2-73)

Edonerpic maleate (T-817MA)

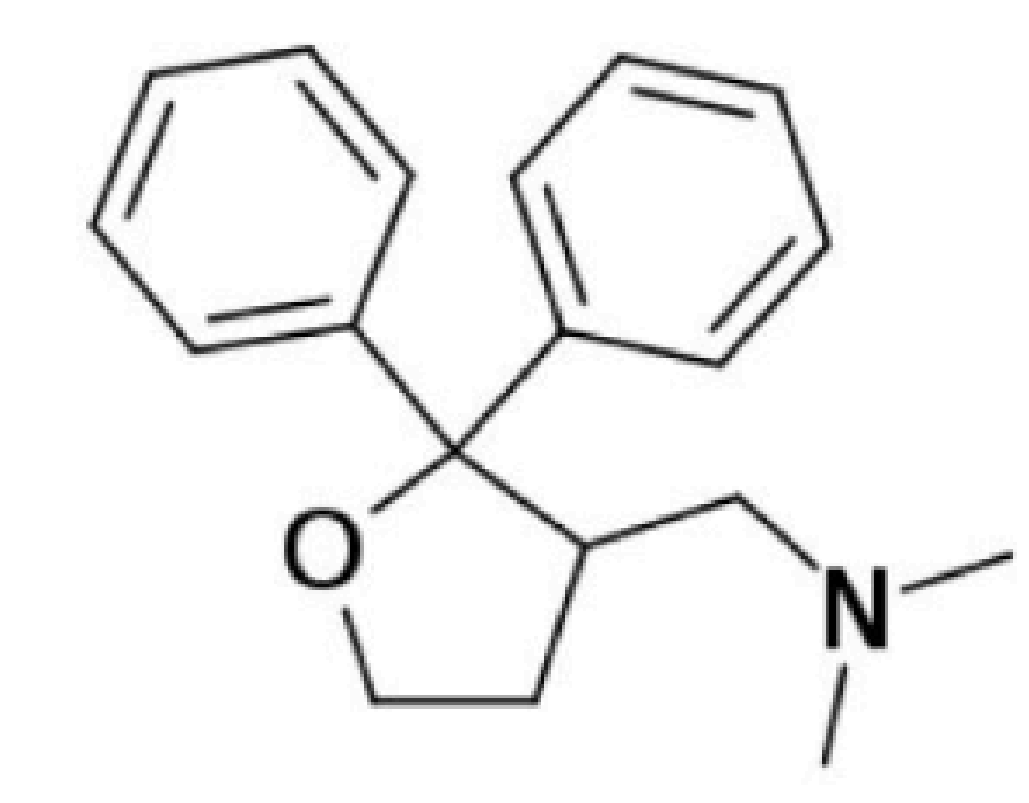

(-)-MR22

(2)

Igmesine (JO-1784)

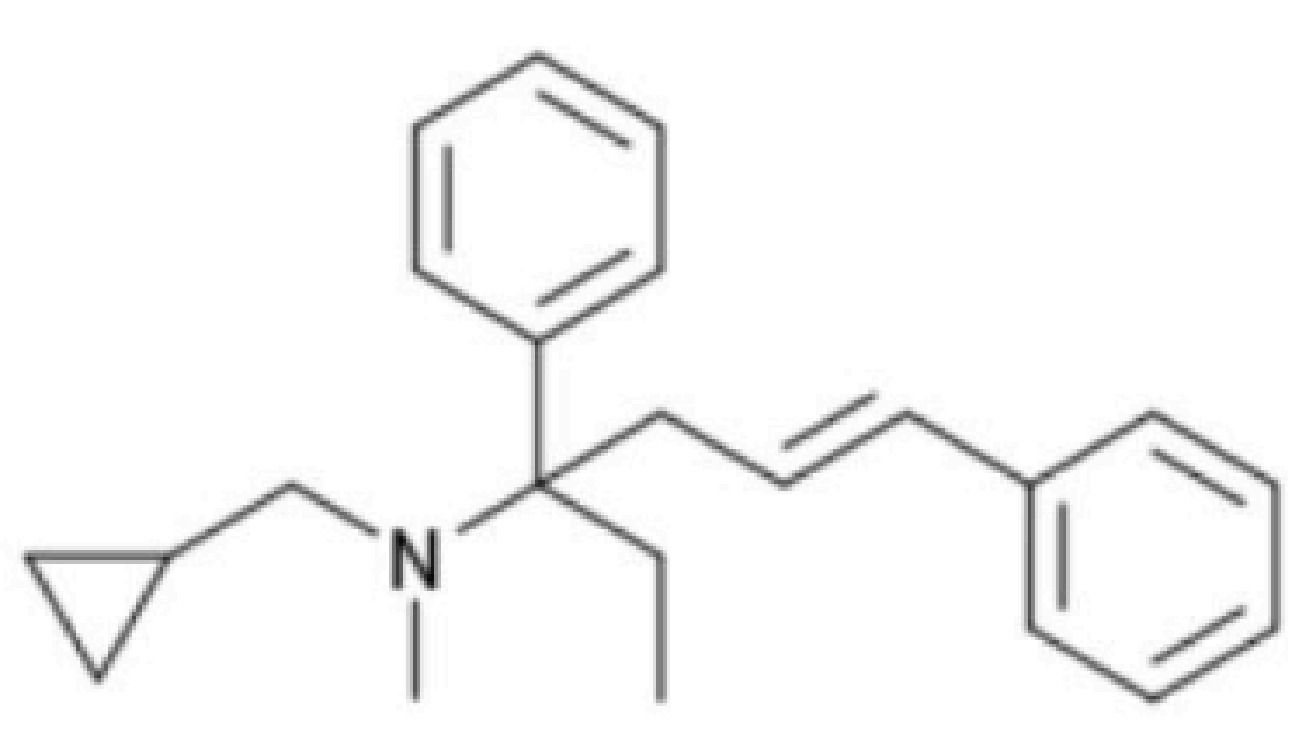

BD737

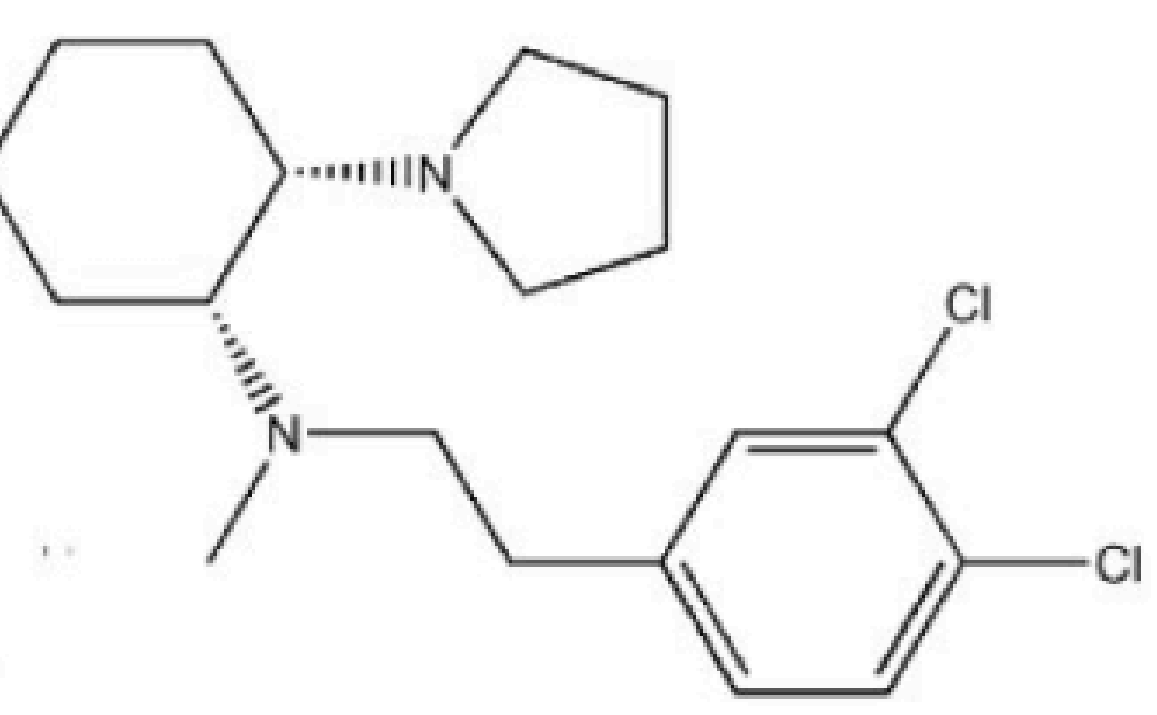

Memantine

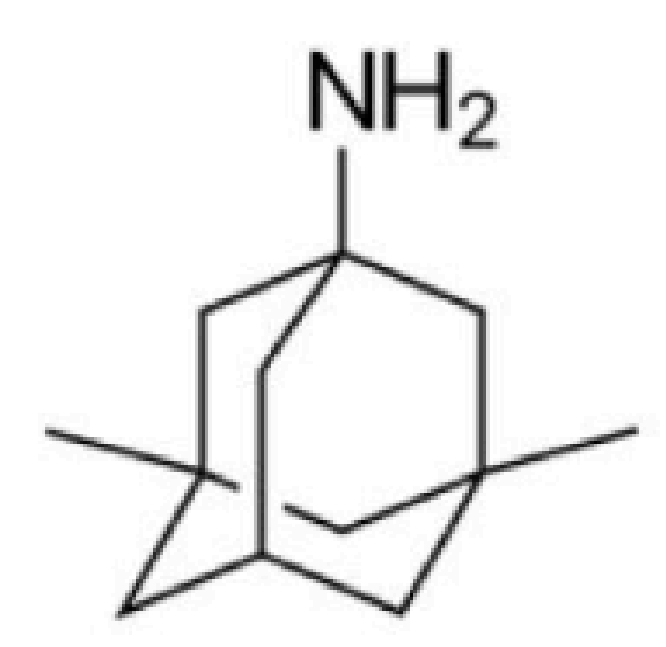

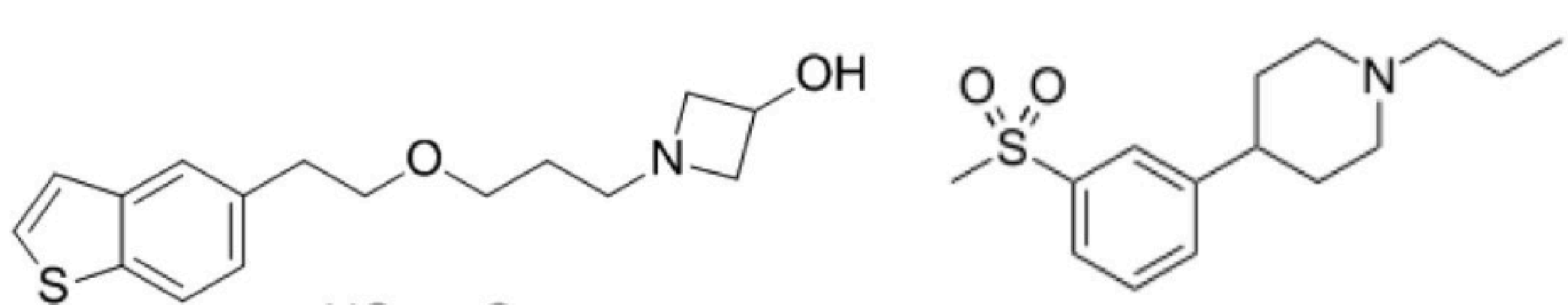<smiles>O=C(O)/C=C\C(=O)O</smiles>

Fabomotizole

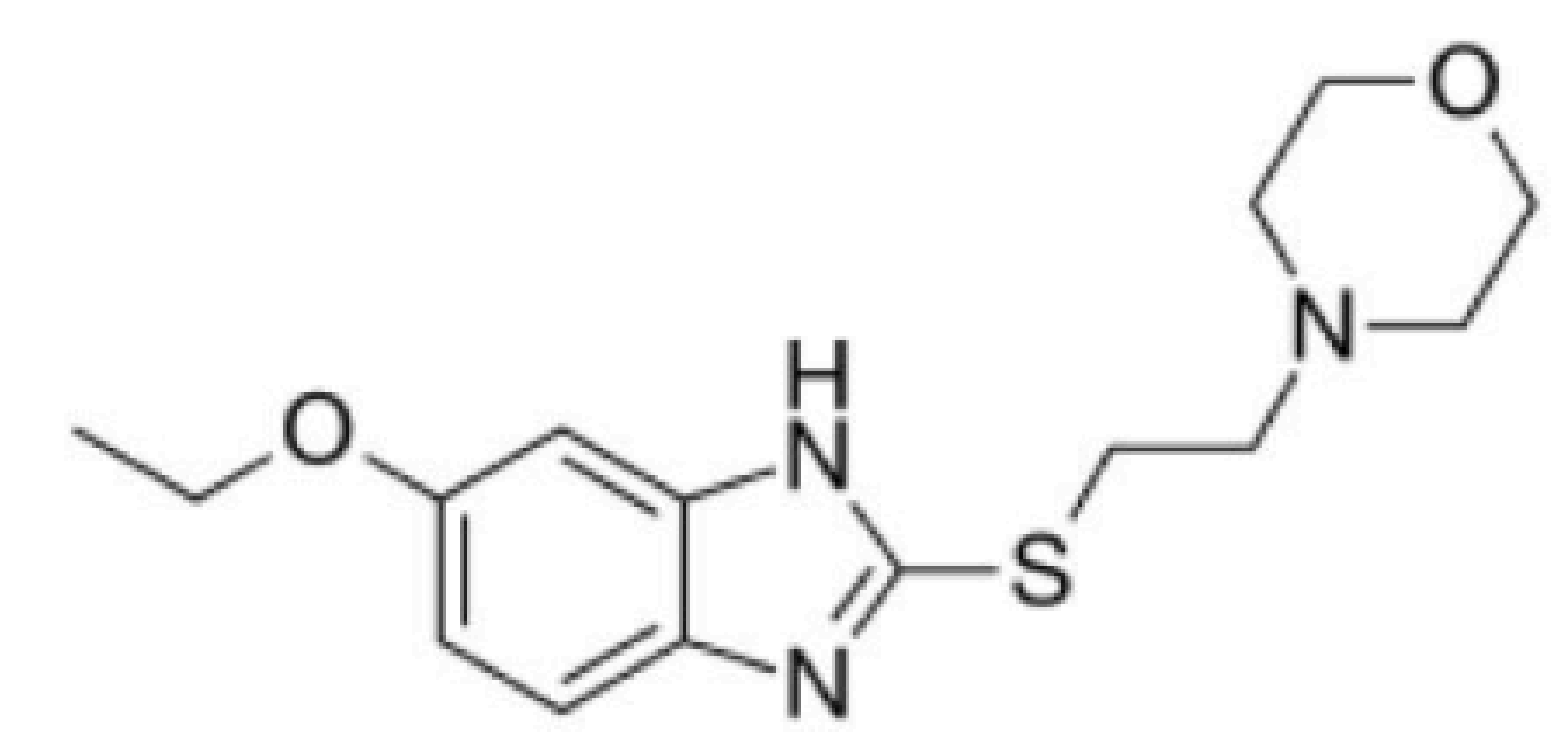

Alazocine ((+)-SKF-10,047)

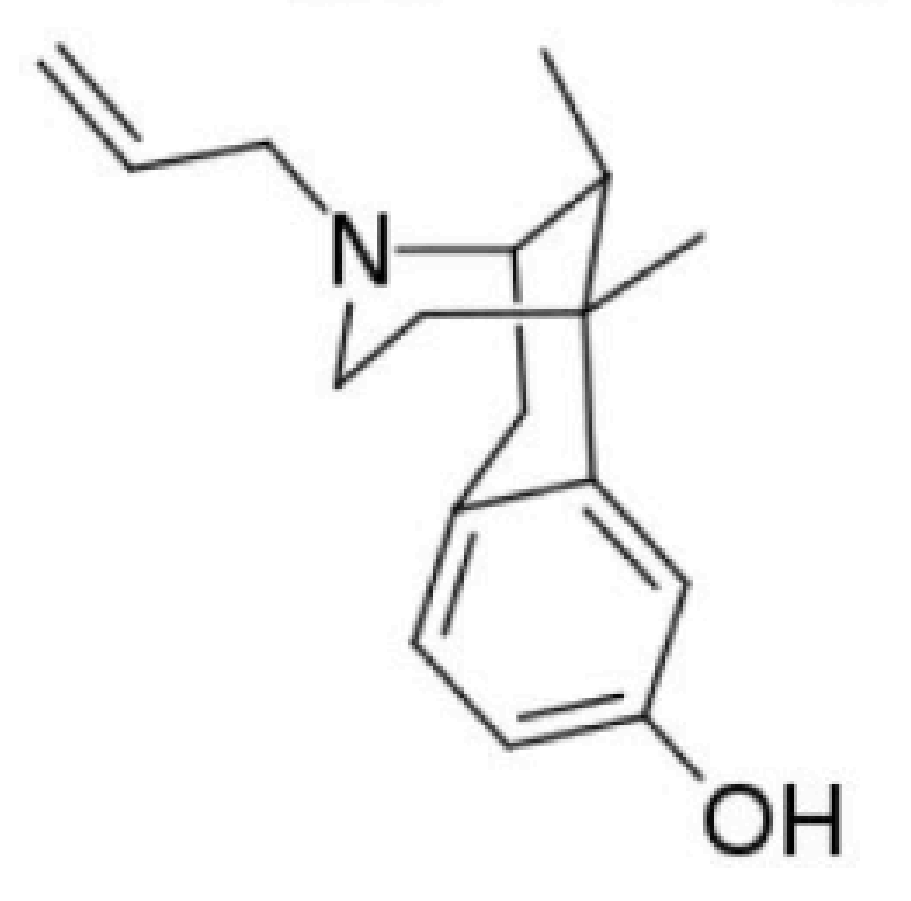

$L-687,384$

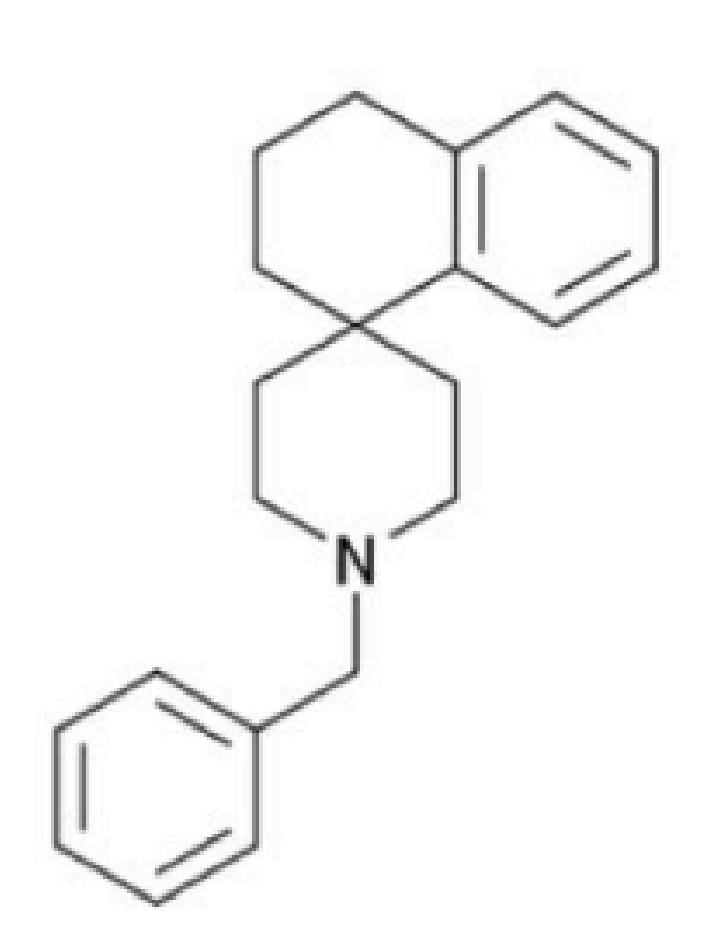

Cutamesine (SA4503)

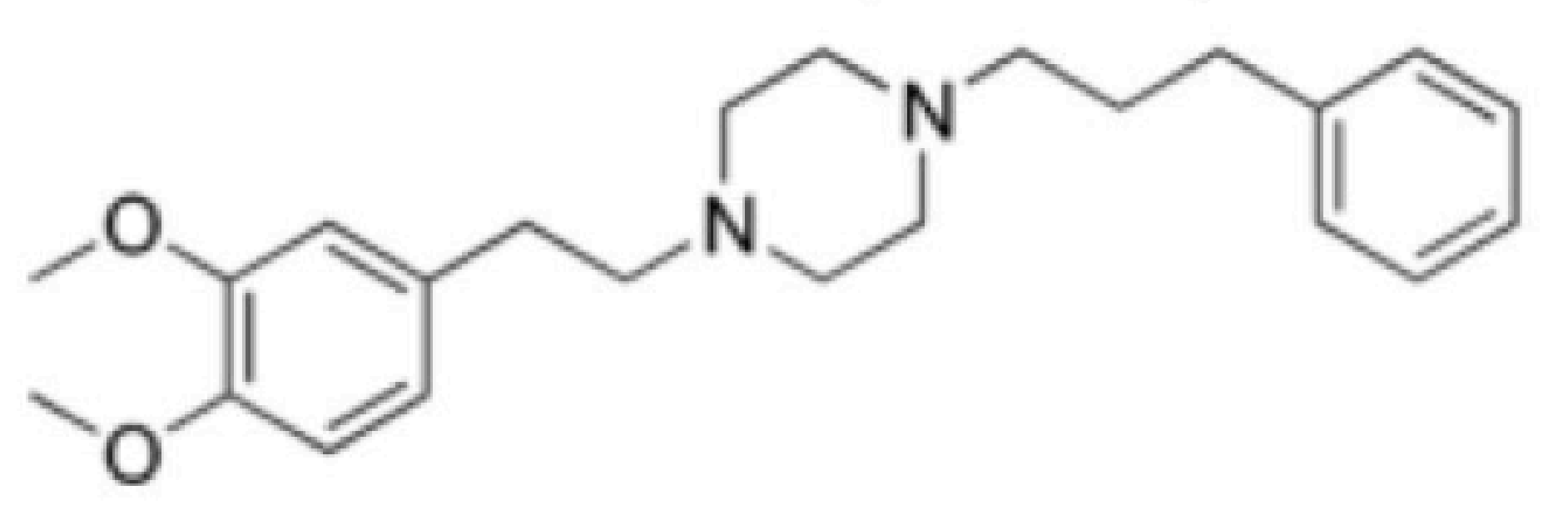

PRE-084

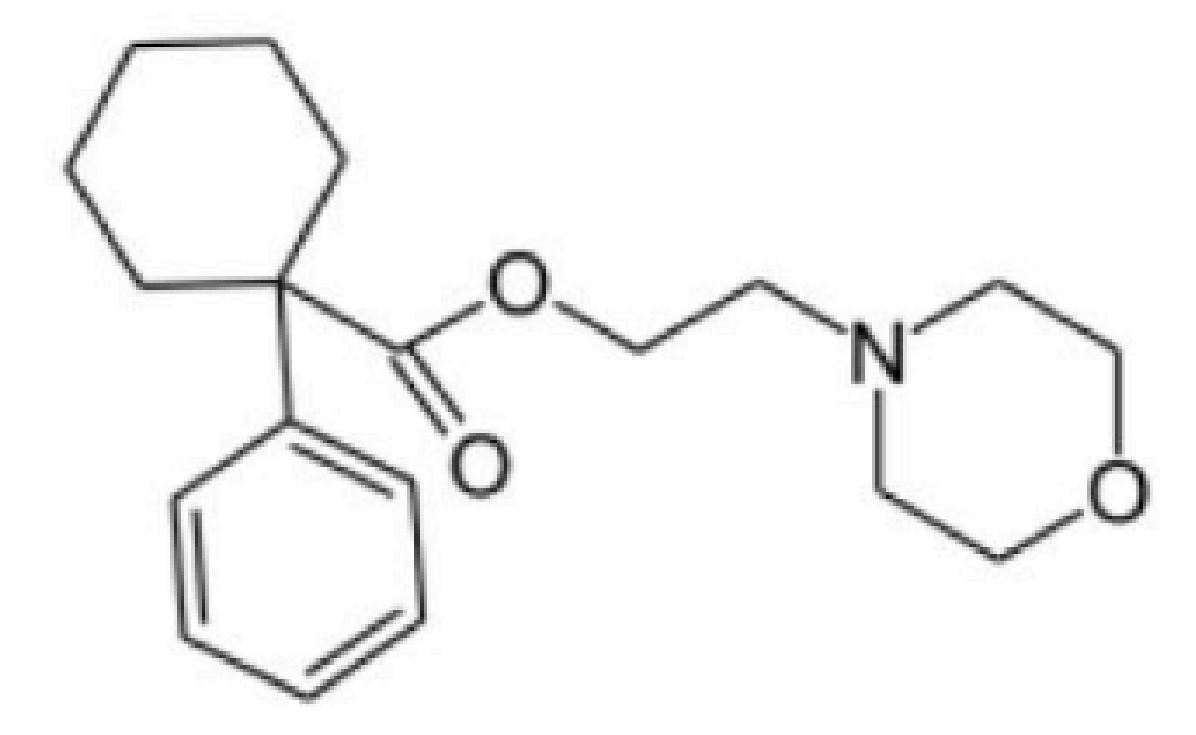

ANAVEX3-71 (AF710B)<smiles>CC1SC2(CCN(C)CC2)CN1C(=O)CCc1c[nH]c2ccccc12</smiles>

(+)-pentazocine<smiles>CC(C)=CCN1C2CCC1(C)c1cc(O)ccc1C2C</smiles>
$\mathrm{HO}$<smiles>CCCN1CCCC(c2cccc(O)c2)C1</smiles>

DTG<smiles>Cc1ccccc1NC(=N)Nc1ccccc1C</smiles>

\section{S1R antagonists}

NE-100

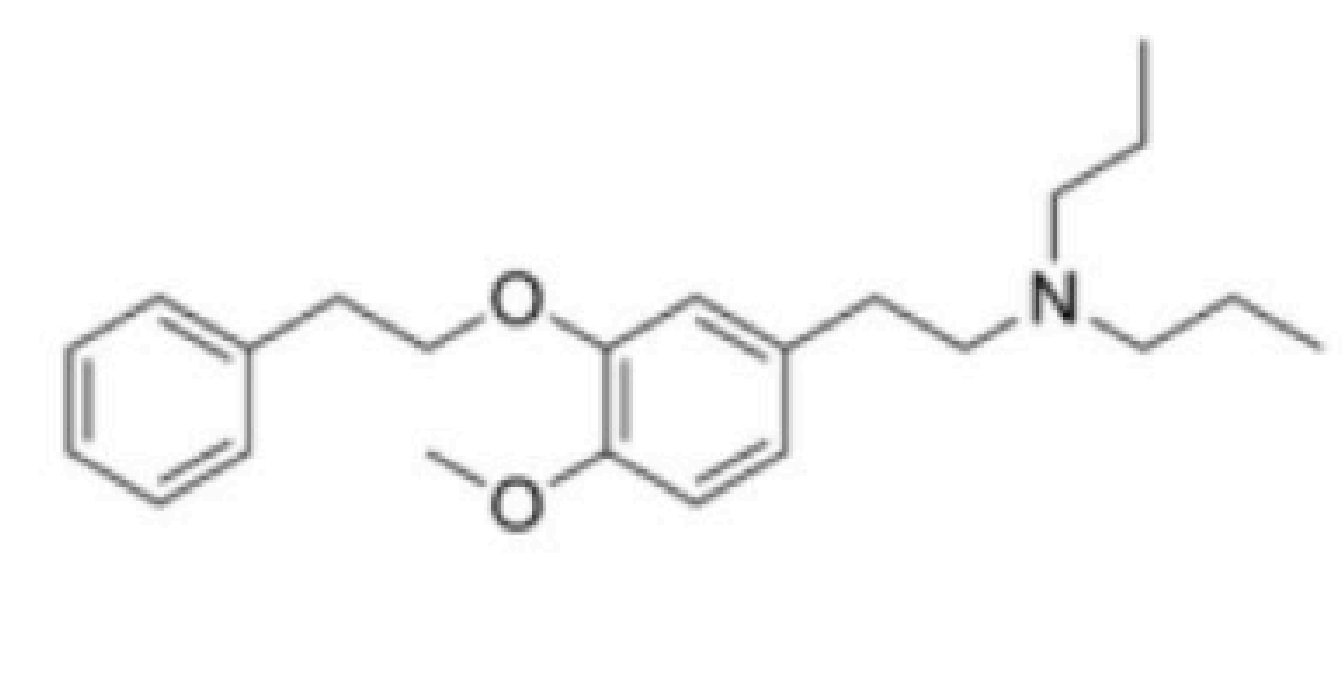

BD1047<smiles>CN(C)CCN(C)CCc1ccc(Cl)c(Cl)c1</smiles>

$S 1 R$ positive modulators<smiles>[R][CH]C([R])=O</smiles>

\section{Fenfluramine}

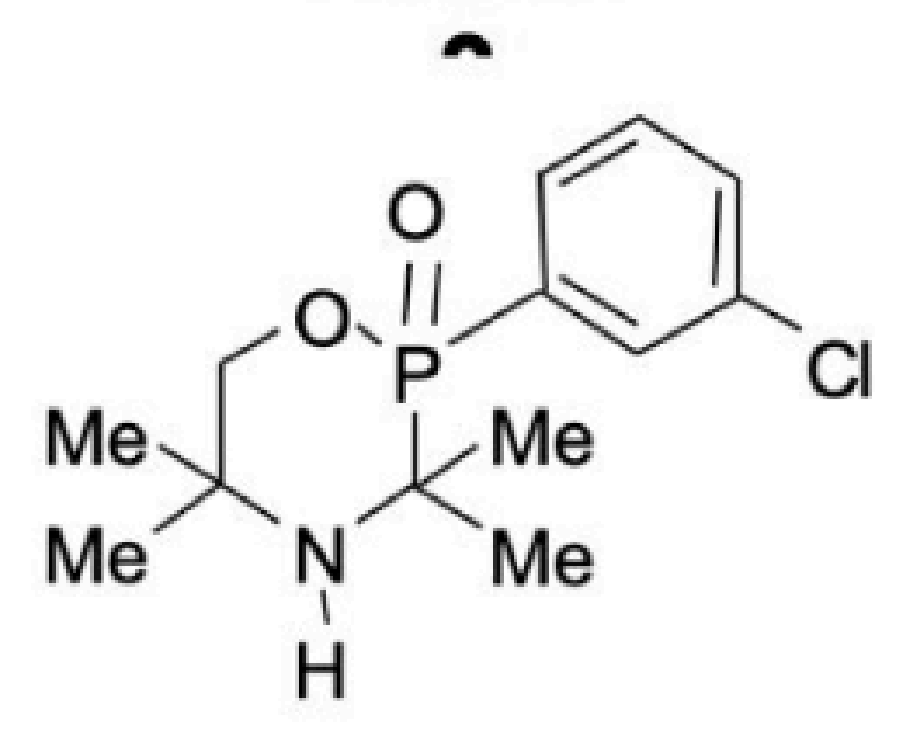<smiles>CCNC(C)Cc1cccc(C(F)(F)F)c1</smiles> 


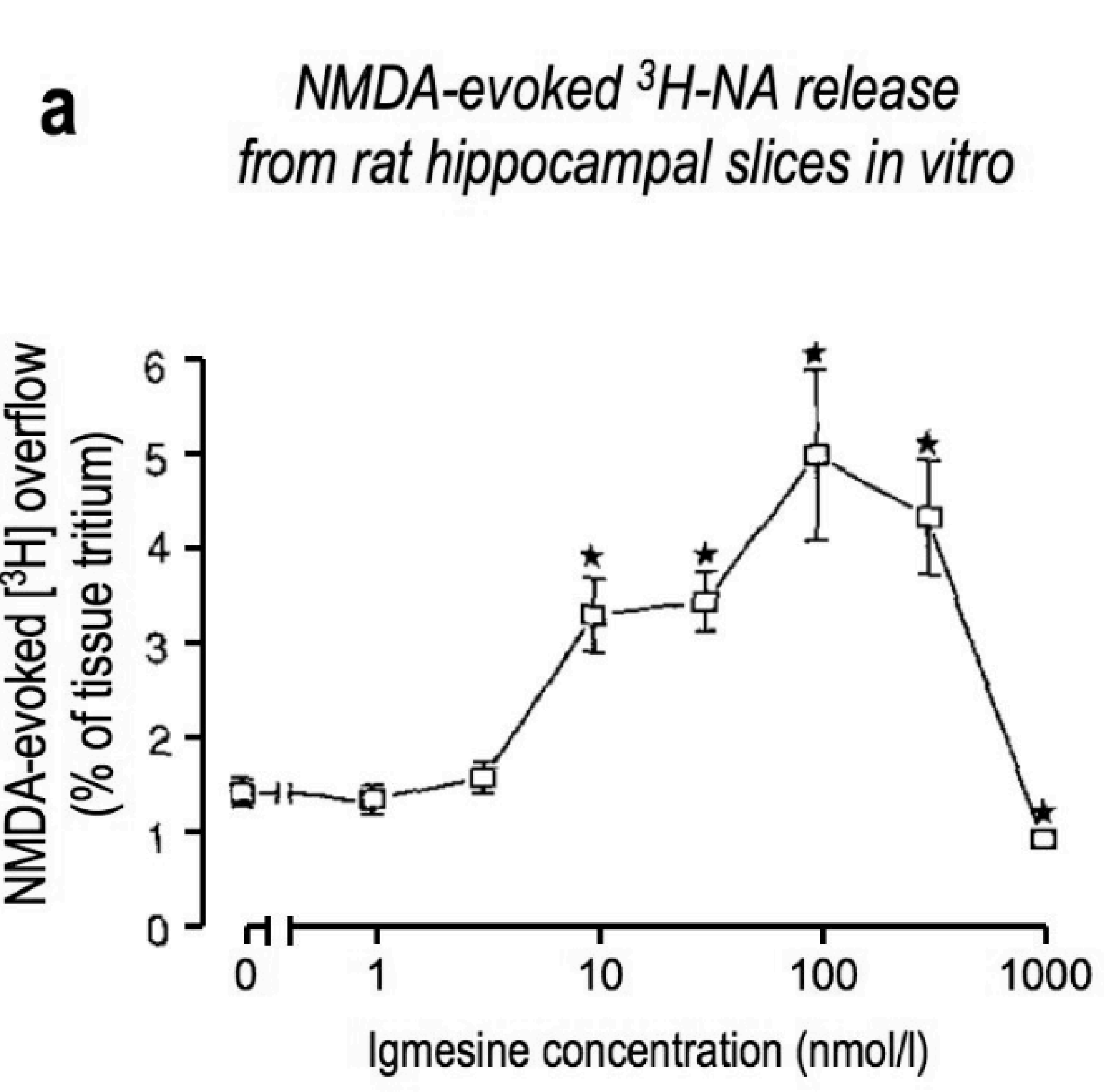

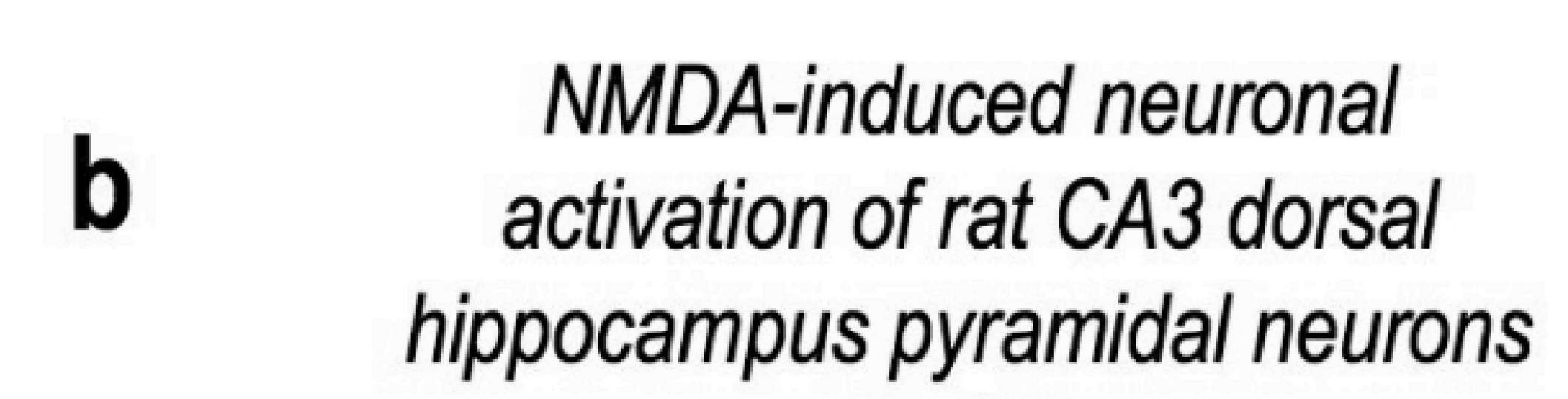

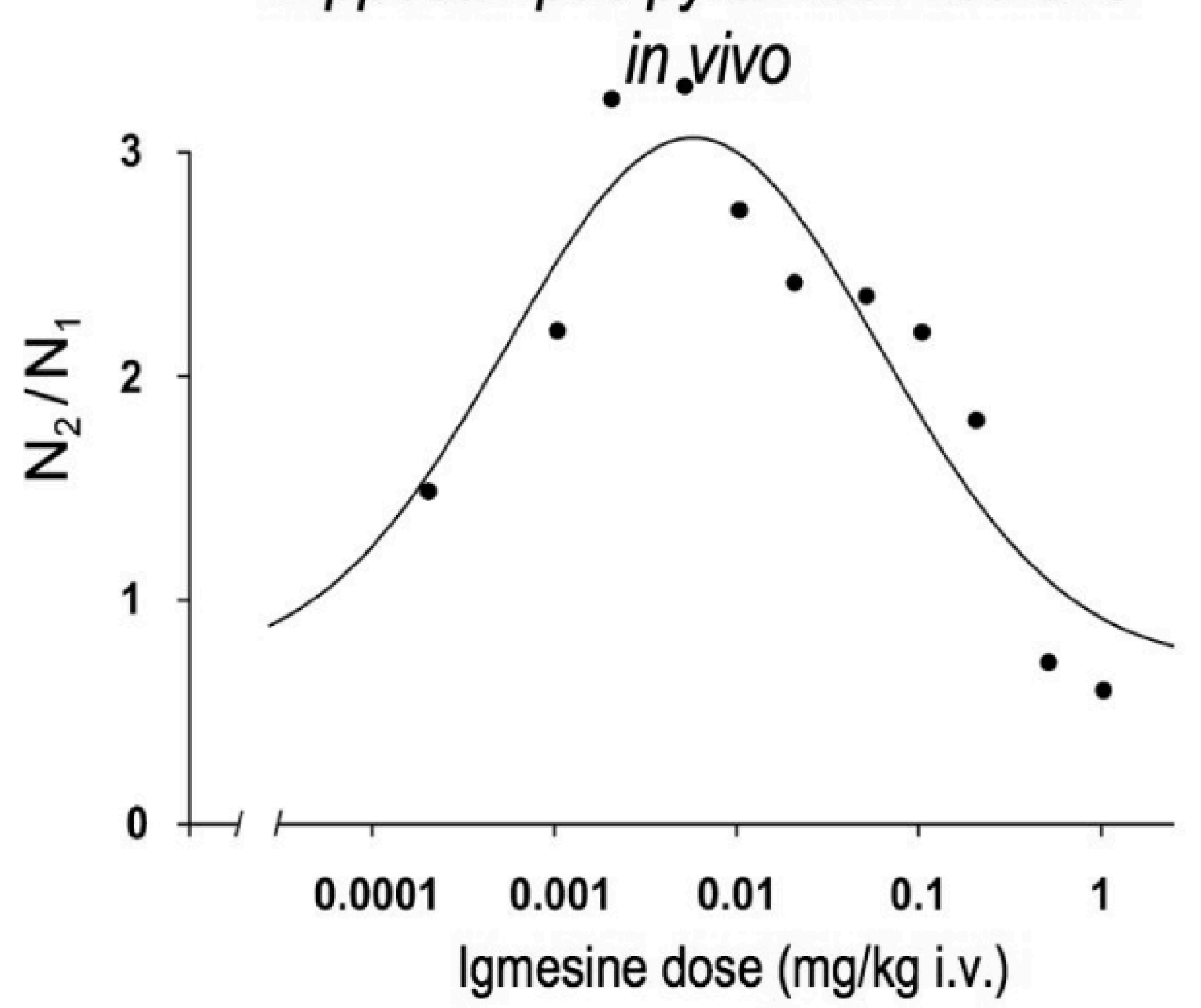

\section{Firing rate of rat dorsal raphe nucleus 5-HT neurons in vivo}

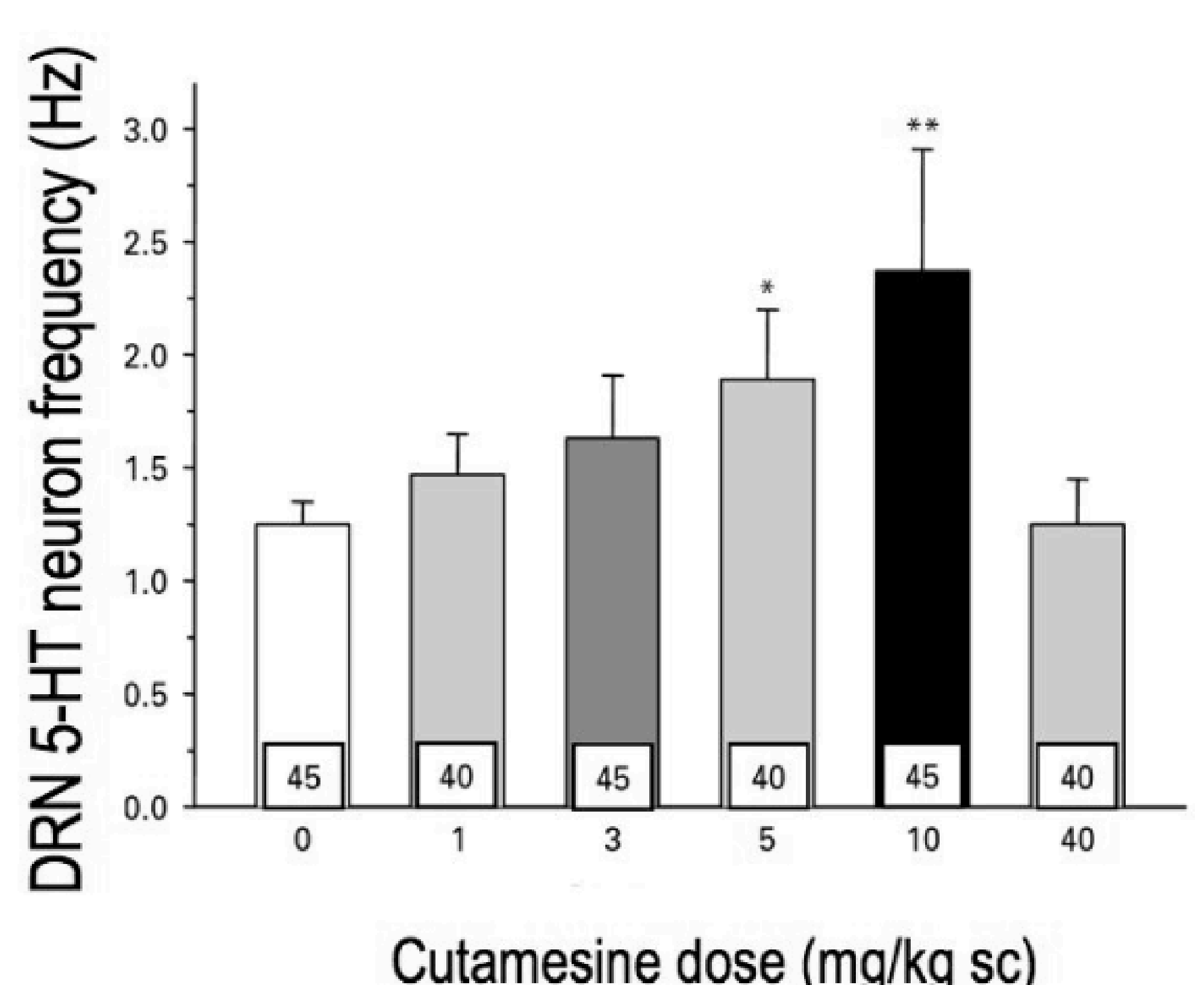

\section{Cellular responses}

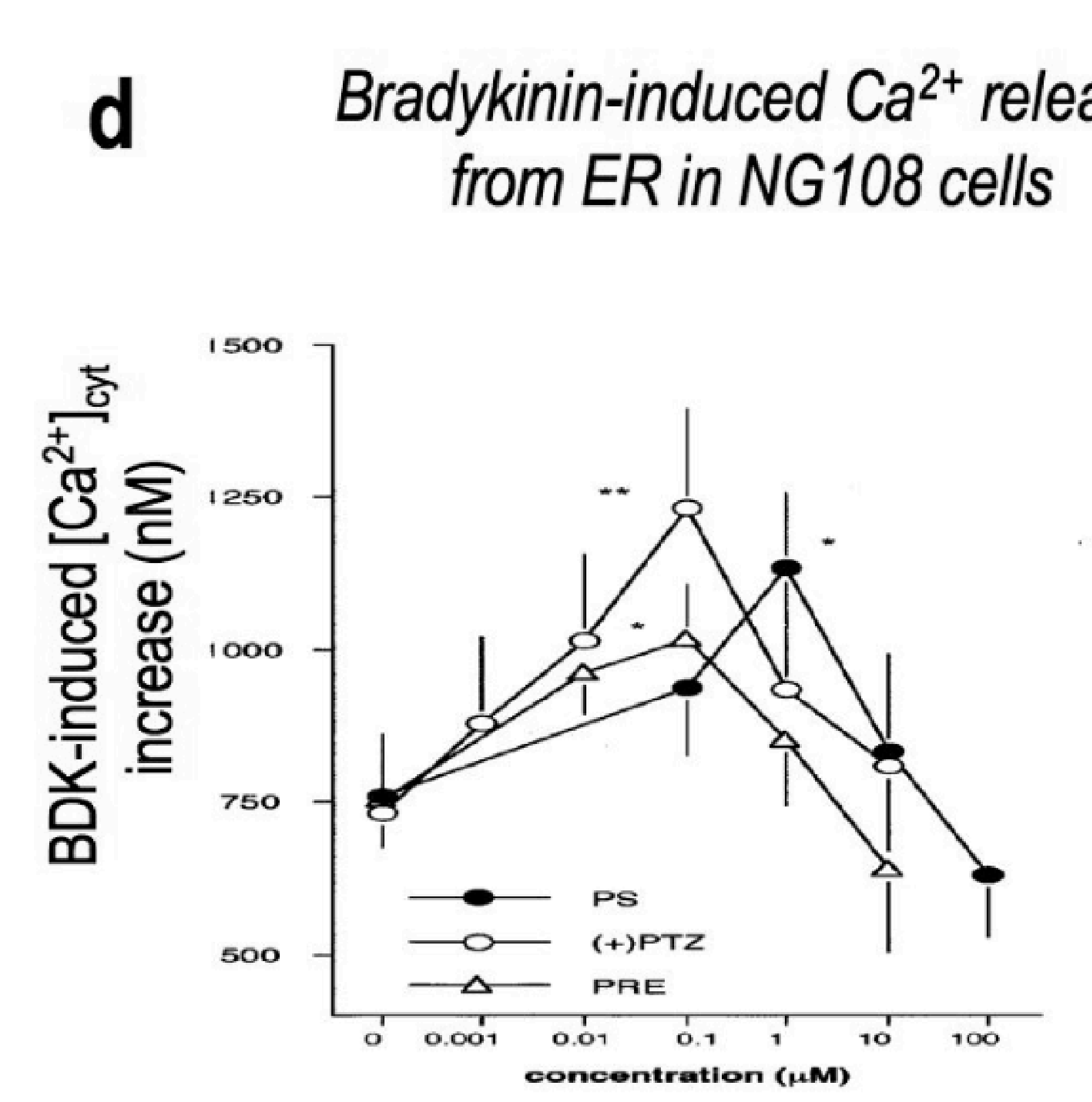

Drug concentrations $(\mu \mathrm{M})$

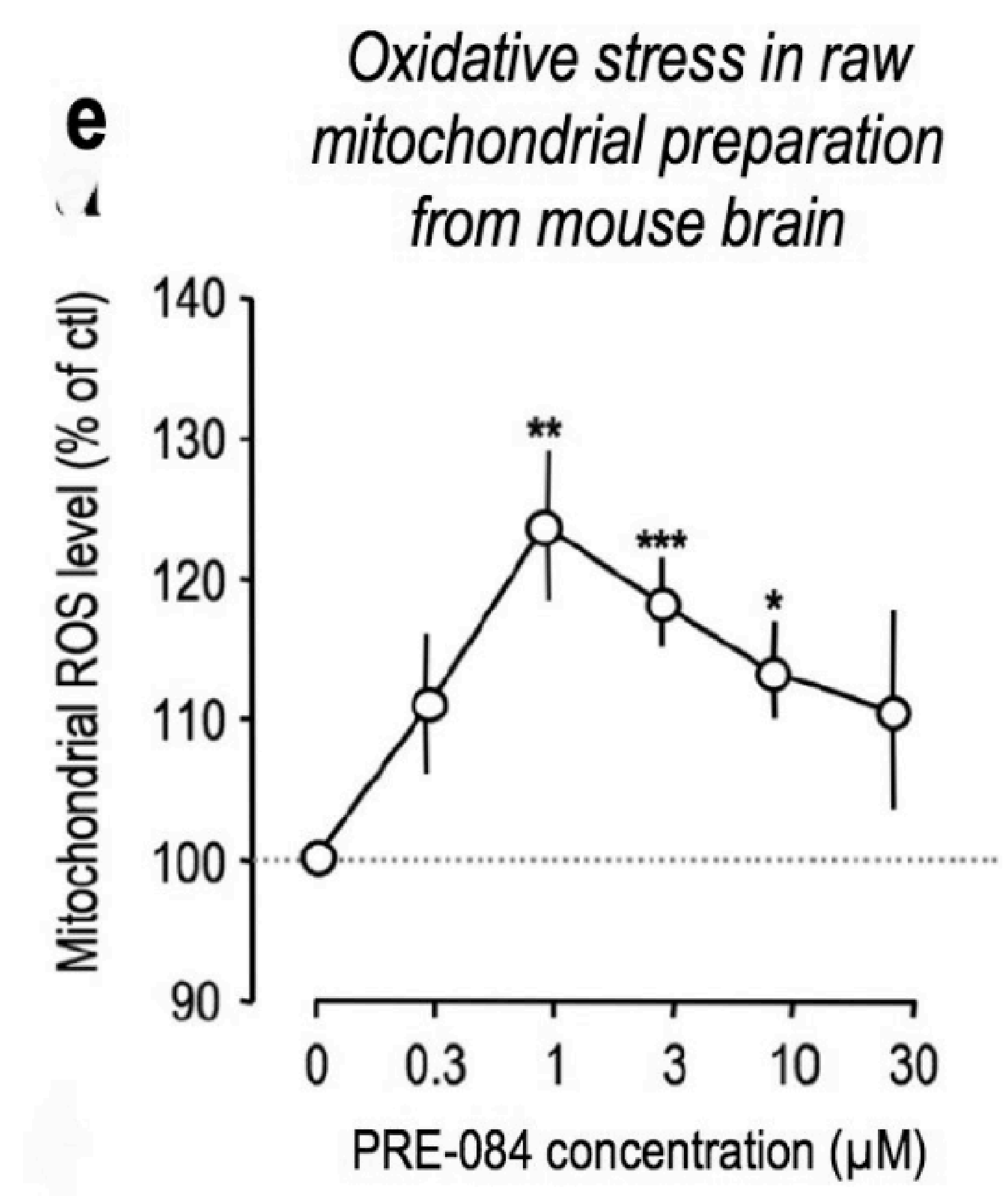

Behavioral/Neuroprotective responses

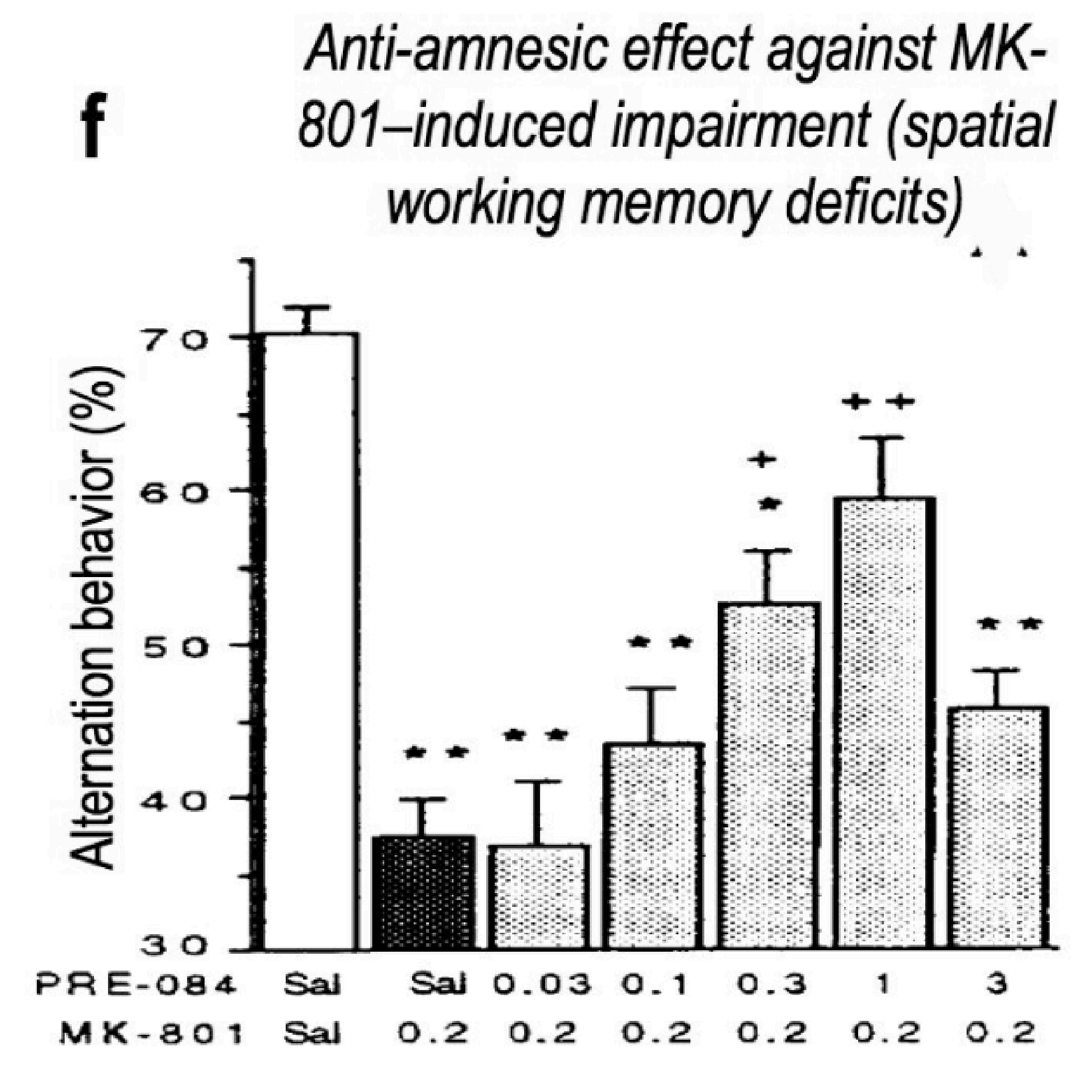

Drug doses (mg/kg sc or ip)

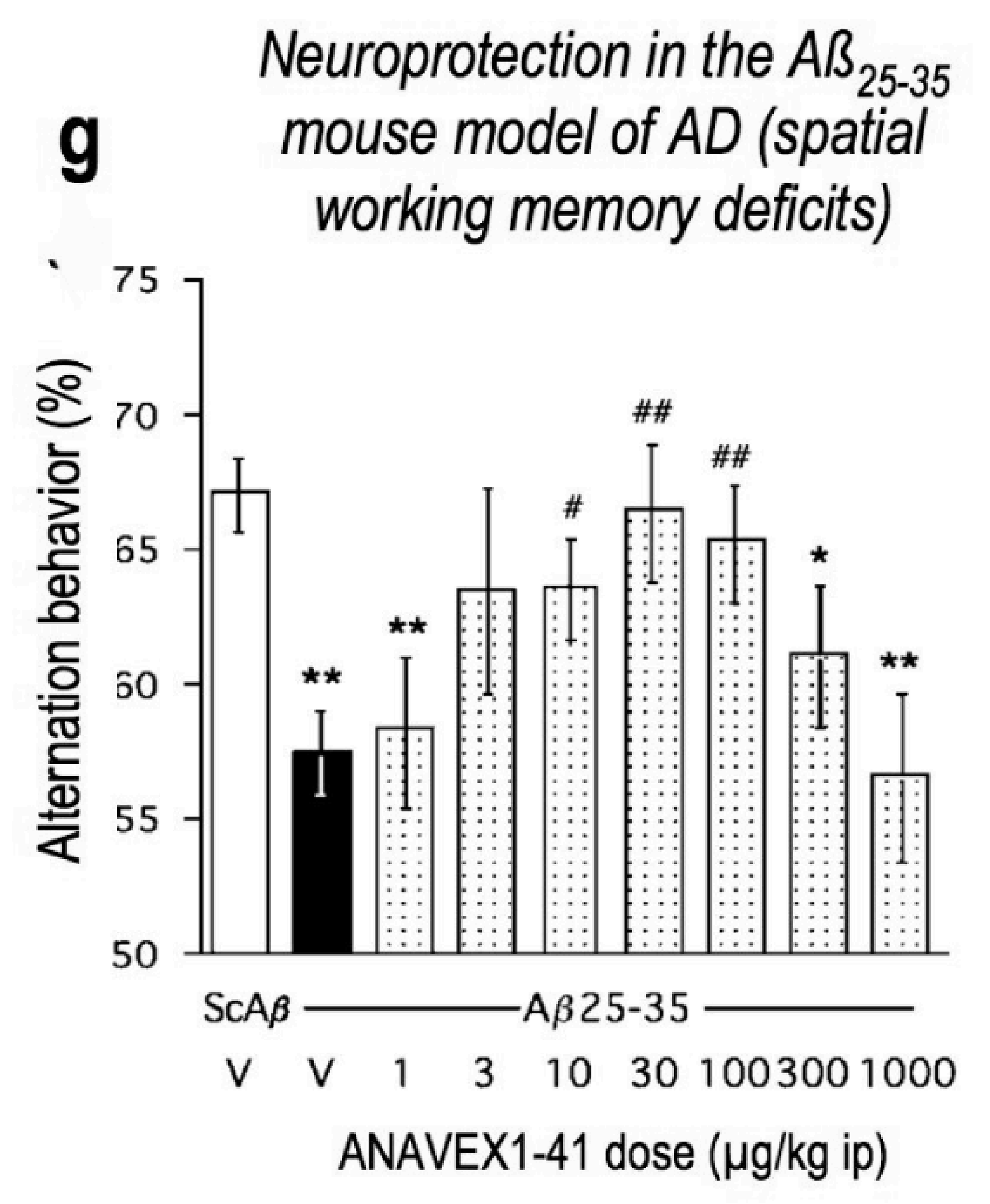

h rat model of $P D$ (histological counting of $\mathrm{TH}+$ cells in the $\mathrm{SNc}$ )

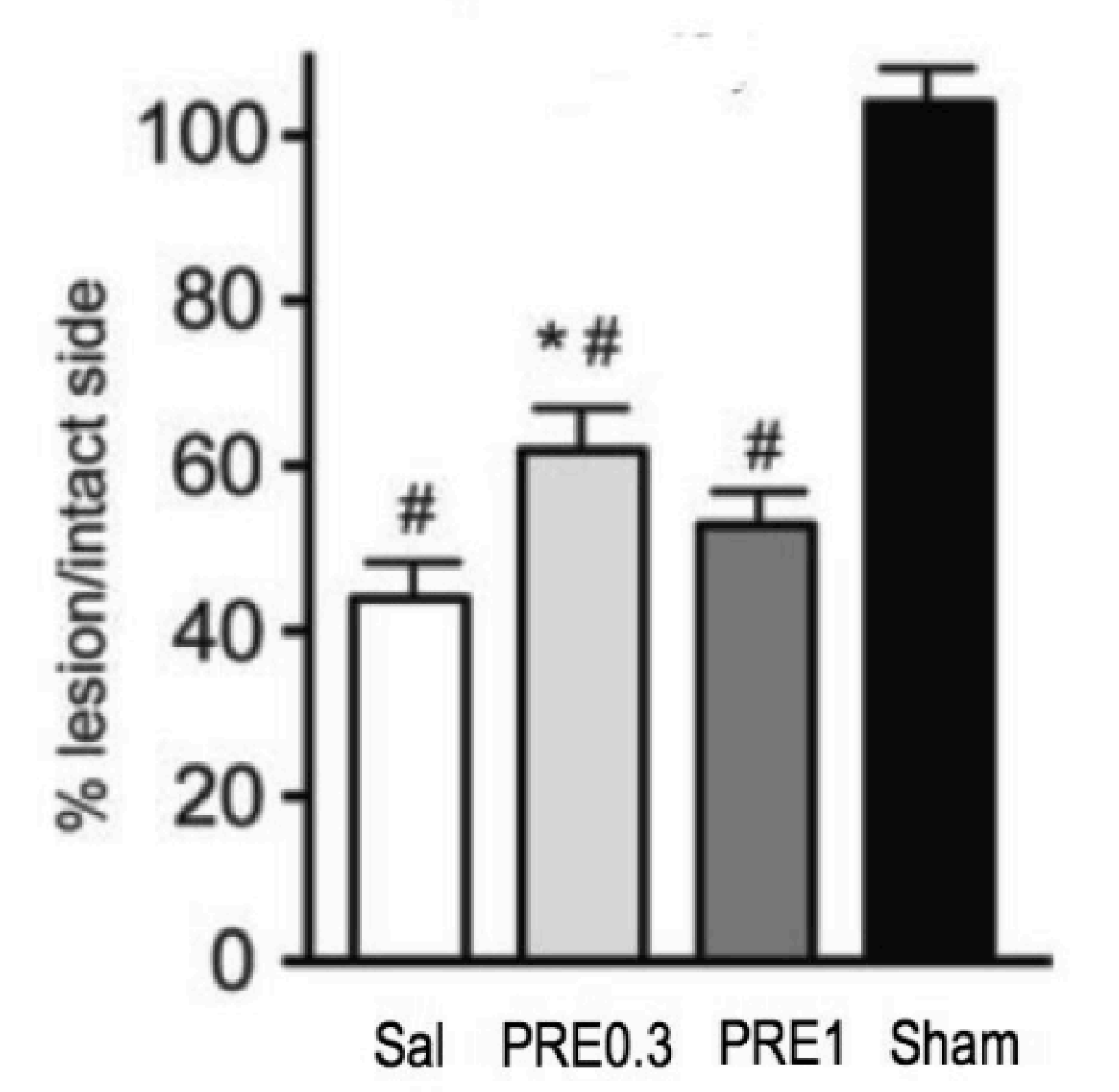

PRE-084 dose ( $\mathrm{mg} / \mathrm{kg} \mathrm{sc})$ 
(a) S1R oligomerization

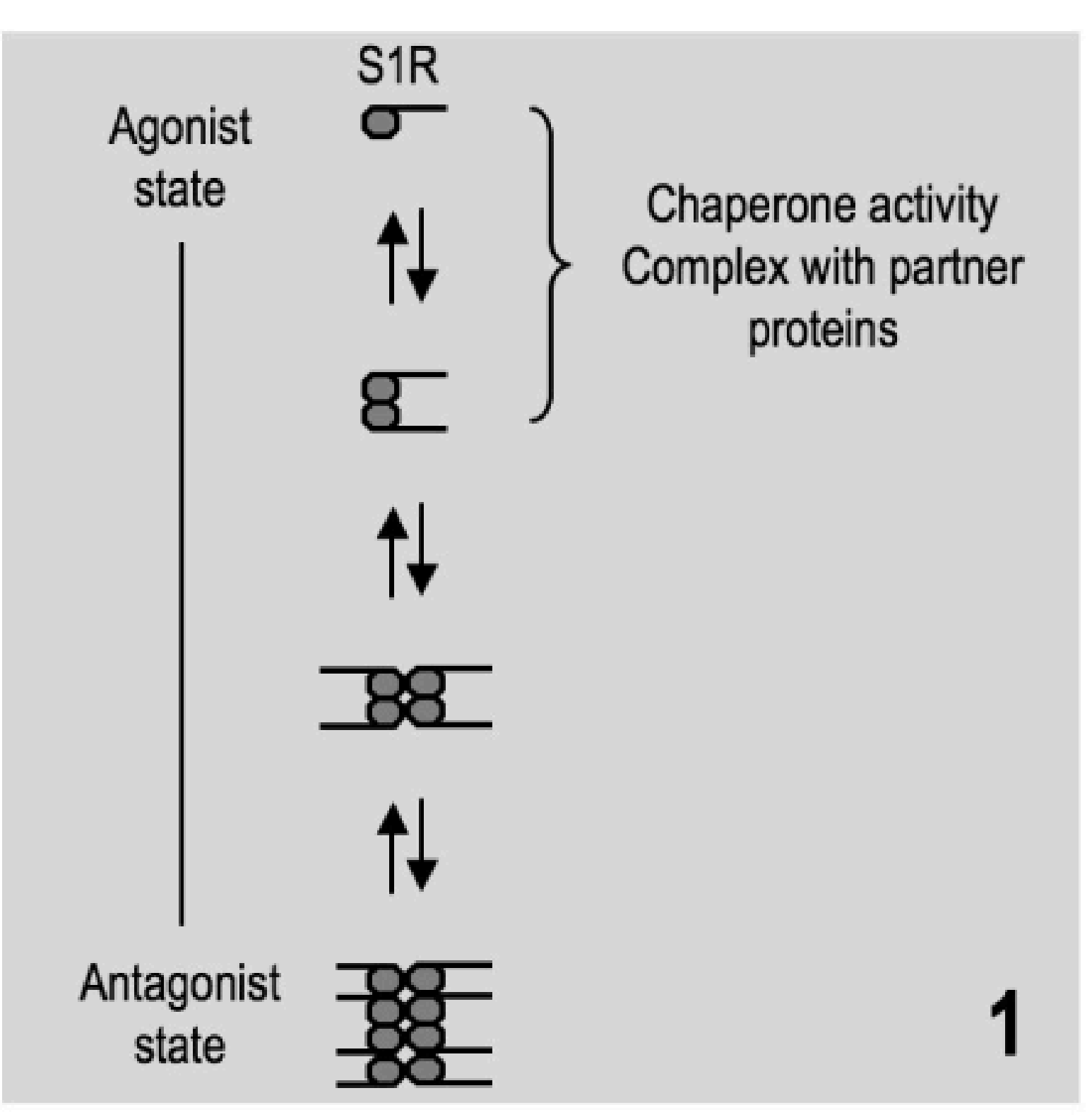

(b) Cellular redistribution

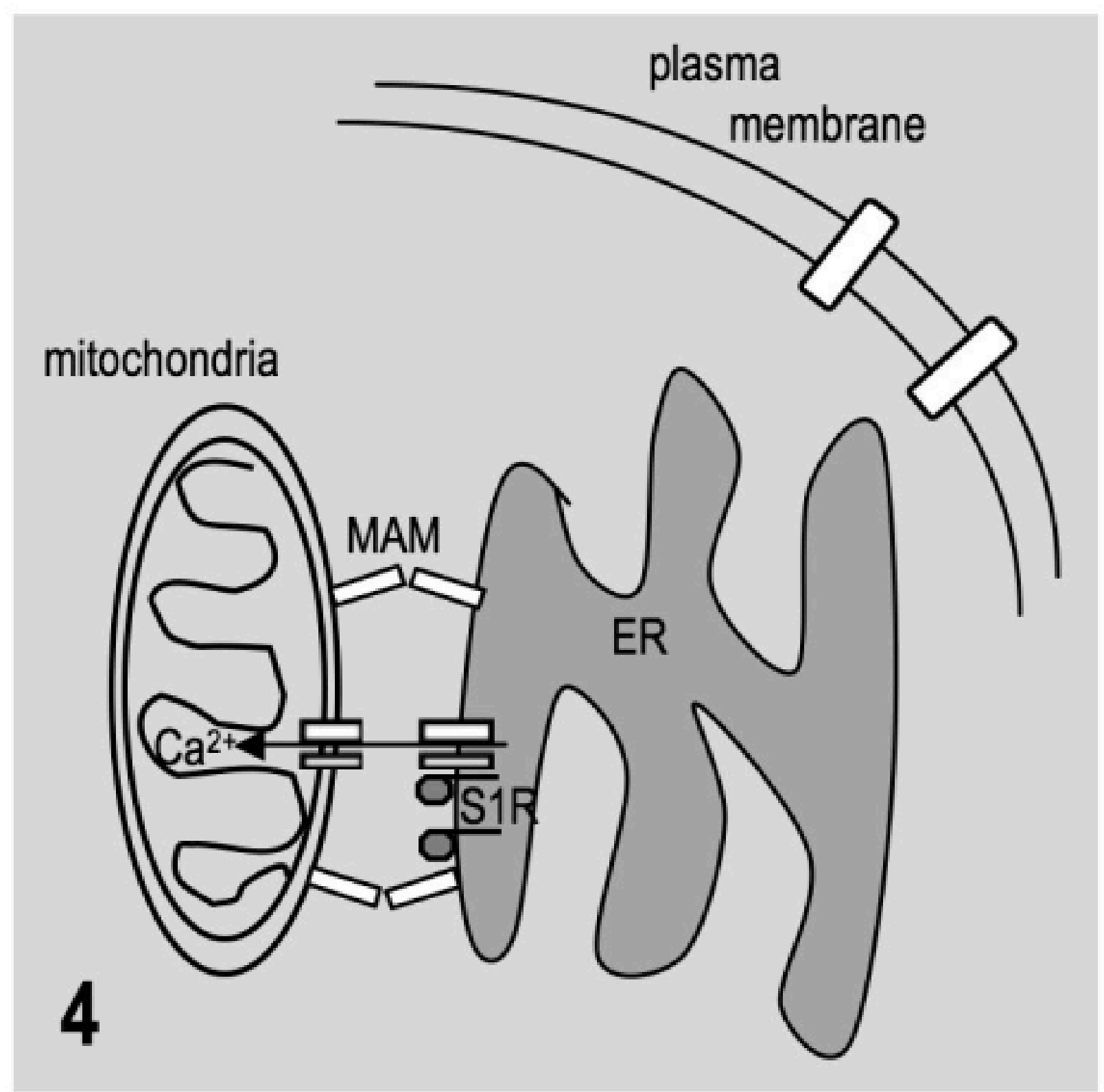

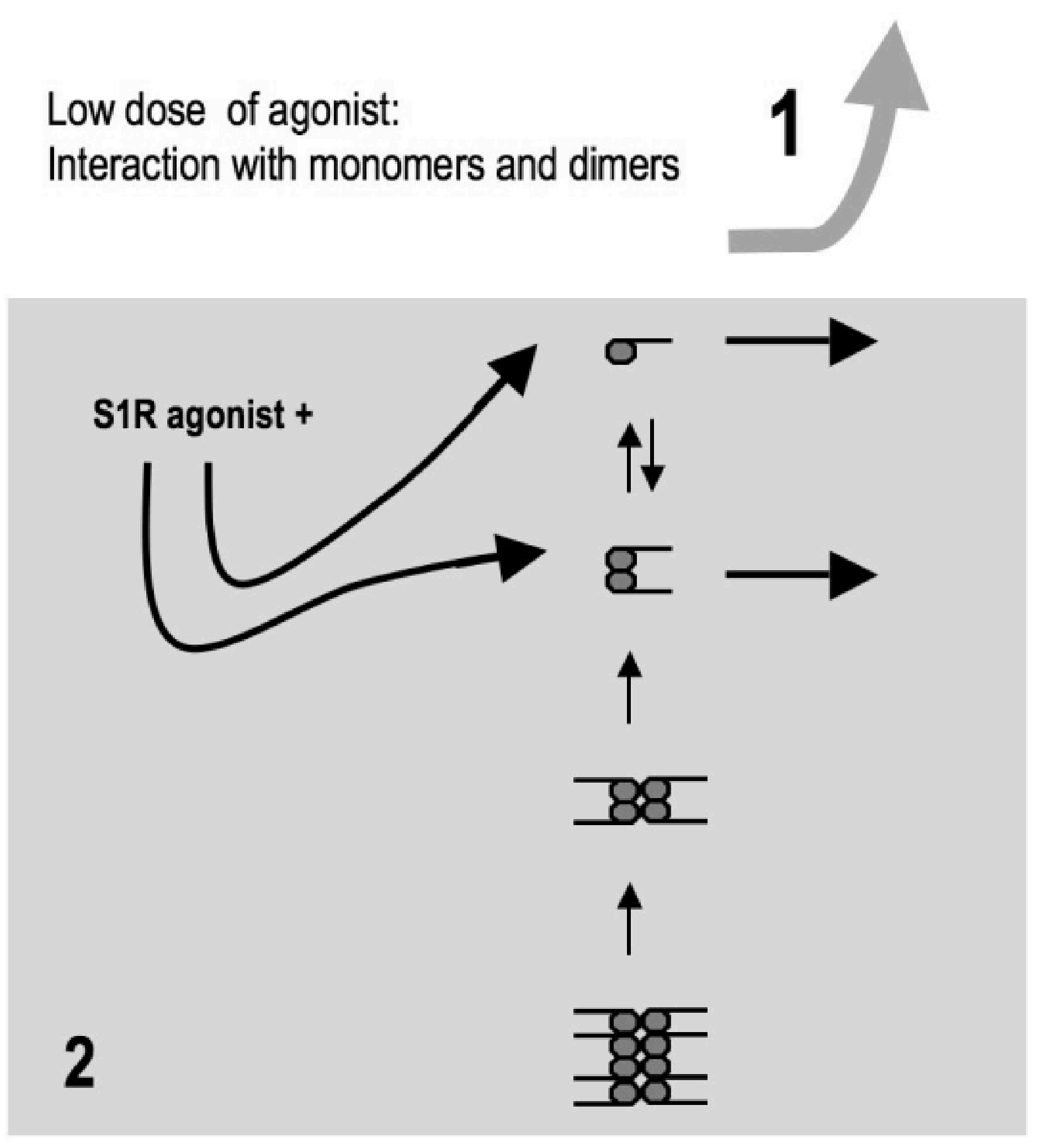

Low dose of agonist: Facilitated action at MAM

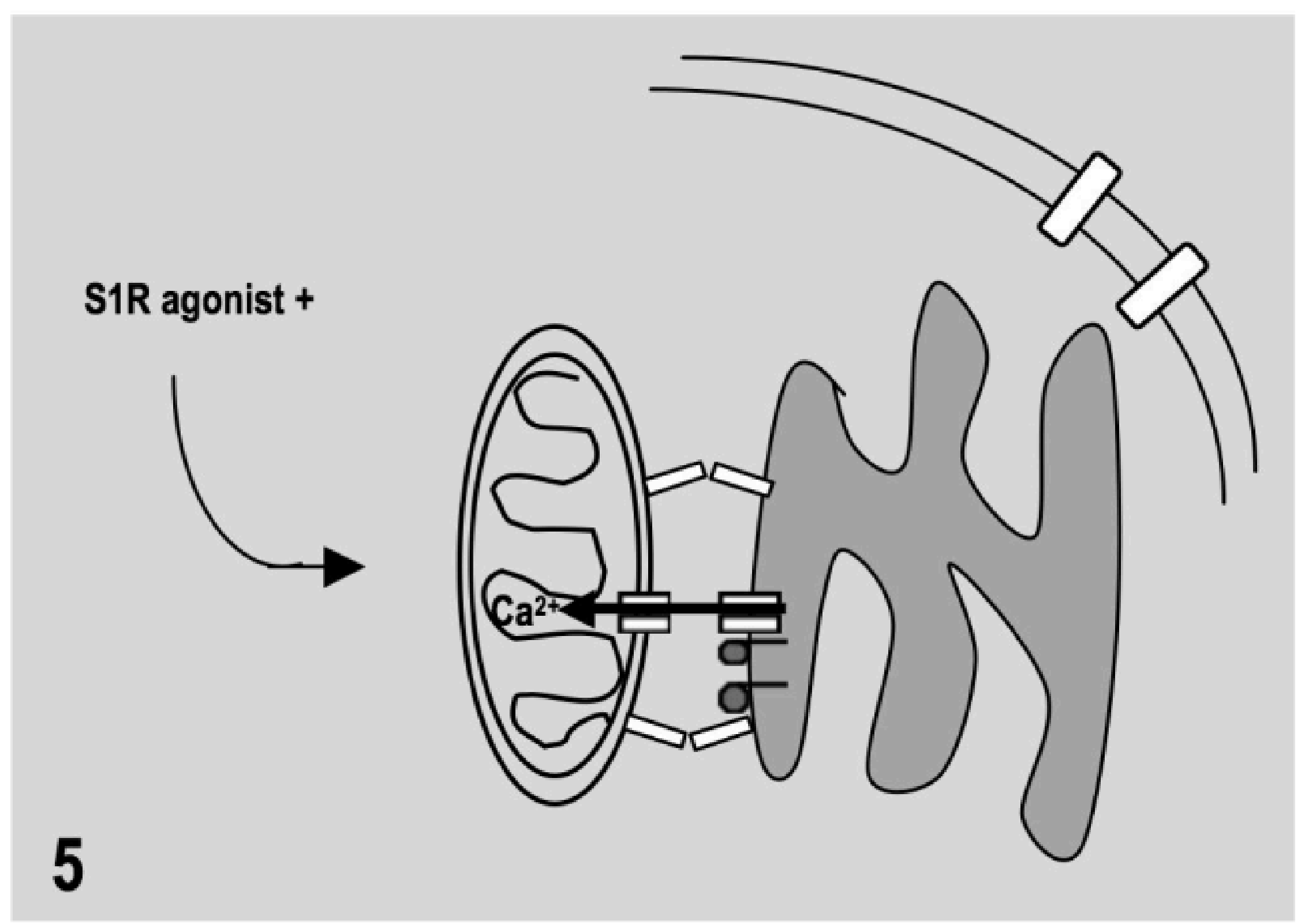

5
High dose of agonist:

Interaction with higher order oligomers

2

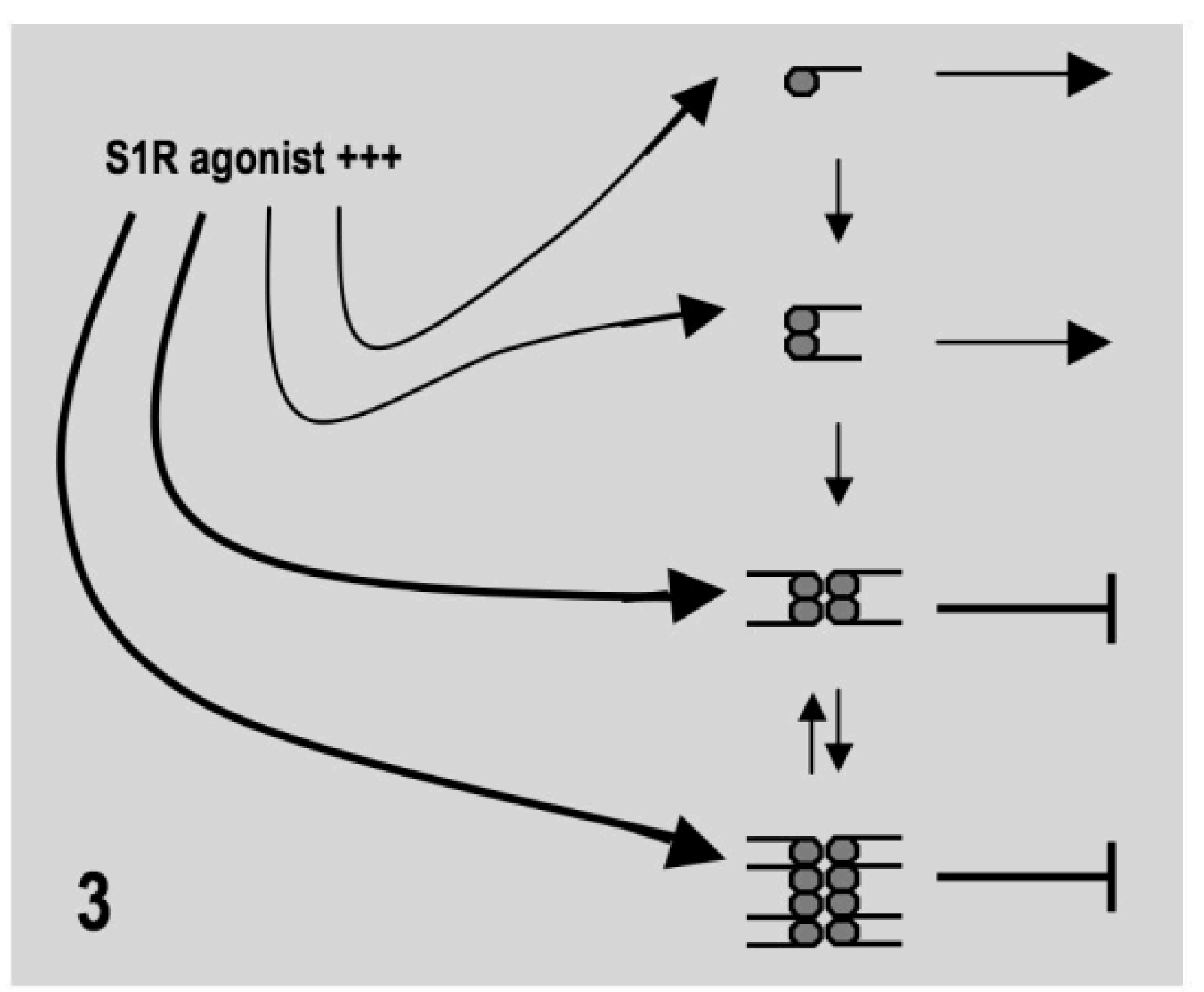

High dose of agonist:

Translocation outside MAM 2

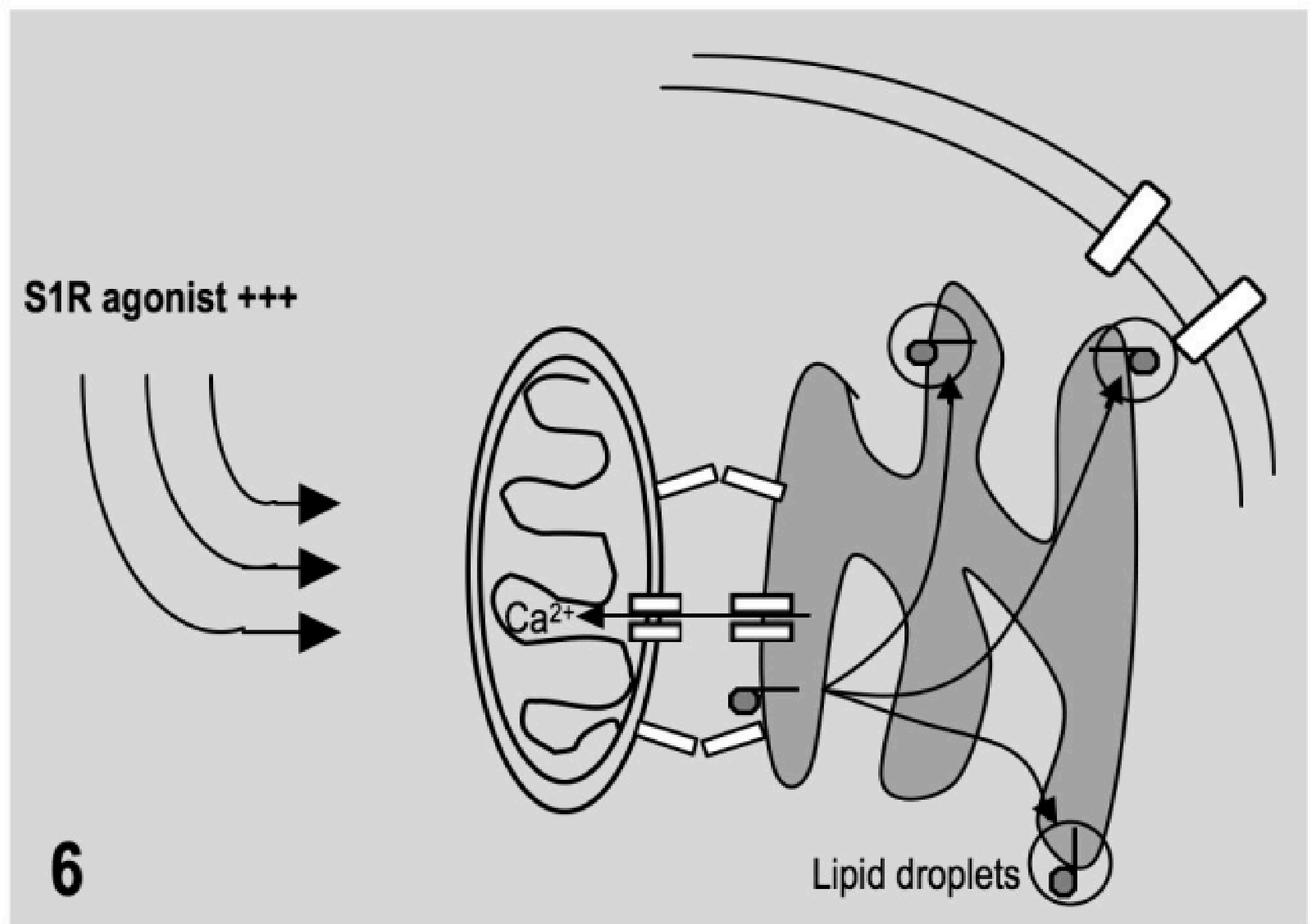

High dose of agonist:
Further BDNF increas

Further BDNF increase and activation of P75NTR 2 (c) BDNF release Low dose of agonist: BDNF increase and TrkB activation

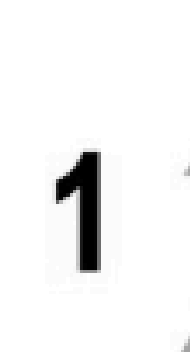

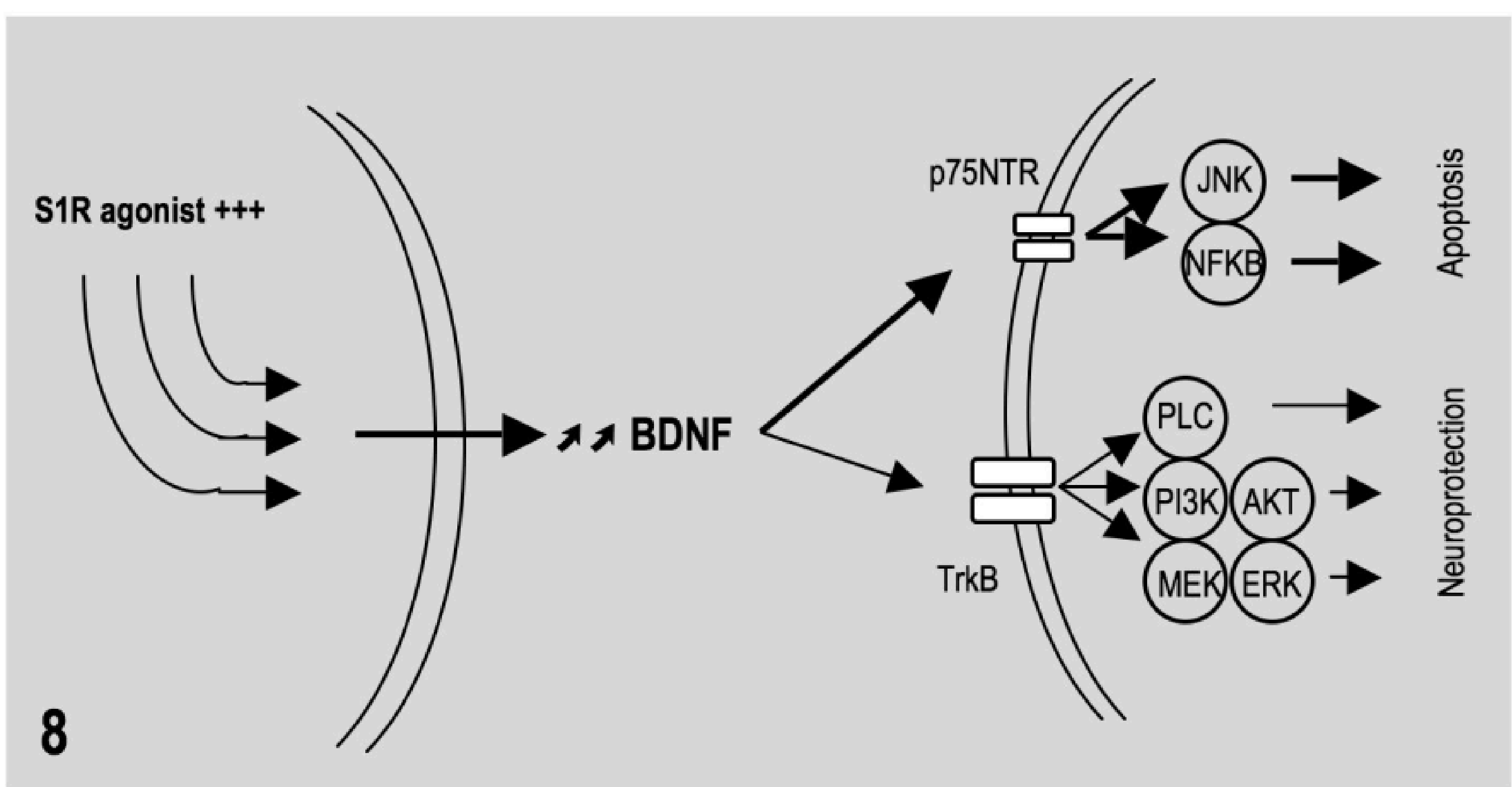

